\title{
Population-Based Algorithms Applied to Brain-Computer Interfaces upon Steady-State Visual Evoked Potentials
}

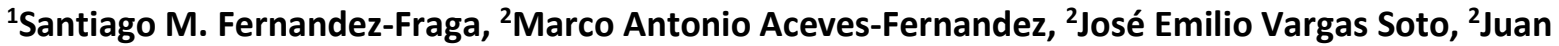 \\ Manuel Ramos Arreguín \\ 1 Computer Systems Department, Instituto Tecnológico de Querétaro, Querétaro, México \\ 2Faculty of Engineering, Universidad Autónoma de Querétaro, Querétaro, México \\ marco.aceves@uaq.mx
}

\begin{abstract}
The development of brain-computer interfaces based upon steady-state visual evoked potentials (SSVEP) requires the processing of electroencephalogram signals to detect brain activity triggered on the occipital region of the scalp caused by visual stimuli. Different algorithms based on stochastic and analytical processes have been proposed. However, most of them involve complex transformations and are highly susceptible to local errors. The present work presents algorithms based upon population to optimize the dimensionality of the characteristics of electroencephalogram signals focusing on SSVEP. Populationbased algorithms are substantiated on the collective behavior of individuals observed in nature, such as flocks of birds, fish populations and some microorganisms, in order to find optimal solutions. This work shows the algorithms of optimization of particle swarm optimization, ant colony optimization, genetic algorithm and differential evolution algorithms in order to generate an optimum subset of features that improves the identification of features of electroencephalogram signals. Spectral Density of Power, Spectral Coherence methods and the computational cost between these algorithms are presented as measure of comparison.
\end{abstract}

Keywords: Population-Algorithms; EEG signal processing; BCI-SSVEP; Particle Swarm Optimization; Ants Colony Optimization; Genetic Algorithm; Differential Evolution.

\section{Introduction}

One of the most common applications of artificial intelligence (Al) is the search for the optimal solution in highly complex problems, both in continuous and discrete spaces. An optimization algorithm is a numerical method that finds a value $\theta_{\mathrm{i}} \in \mathrm{R}^{\mathrm{n}}$, where $R^{\mathrm{n}}$ is an $\mathrm{n}$-dimensional search space, which minimizes or maximizes a function $J(\theta)$, by way of the systematic selection of values of the variable $\theta_{i}$ possibly with some restrictions. The variable $\theta_{\mathrm{i}}$ can be a scalar or a vector of discrete or continuous values called feasible functions, while $J(\theta)$ is called the objective function. A feasible solution that minimizes or maximizes the objective function is called an optimal solution. One type of optimization problem is the one that requires combinations of values, which is called combinatorial optimization (Muñoz, et al., 2008). In general, in the study of neurosciences and complex biological systems, it is often necessary to adapt mathematical models with a large number of parameters or highly complex data sets (Svensson, et al., 
Santiago M. Fernandez-Fraga, Marco Antonio Aceves-Fernandez, José Emilio Vargas Soto, Juan Manuel Ramos Arreguín; Population-Based Algorithms Applied to Brain-Computer Interfaces upon Steady-State Visual Evoked Potentials, Transactions on Machine Learning and Artificial Intelligence, Volume 7 No 2 April, (2019); pp: 1-33

2012). Several modern heuristic algorithms have been developed to solve combinatorial and numerical optimization problems. These algorithms can be classified into different groups: constructive methods, local search or population based. Population-based algorithms are sets of elements that mimic their behavior in some phenomenon of nature. These algorithms will be inspired by biological evolutionary processes, in which, a population formed by a group of individuals, of one or more generations, contribute in some way to significant changes in future generations, these changes are carried out in a nondeterministic way (Mishra, et al 2013). Population-based algorithms can be classified into two categories: evolutionary algorithms (EA), and swarm intelligence algorithms (SI) (Mishra, et al 2013). EA resemble natural evolutionary principles to constitute search and optimization procedures. SI algorithms are based on collective behavior of decentralized, self-organized natural or artificial systems, the term swarm is used in a general way to refer to any collection of individuals interacting and cooperating with one another (Mishra, et al 2013).

Non-invasive brain computer interface $(\mathrm{BCl})$ uses electroencephalogram (EEG) signals to capture the electrical activity of the brain associated with some specific activity. $\mathrm{BCl}$ systems are based on a variety of EEG signal characteristics, including slow cortical powers (SCP), oscillatory activity, P300 potentials, motor imaging (IM) and visual evoked potentials (VEP) (Bevilacqua, et al., 2014). In addition, VEP measurements have been developed successfully in terms of performance, speed and accuracy; it requires a shorter training time, are immune to artifacts (blinking, involuntary movements, etc.) and has better signal-tonoise ratio. These measurements are known as Steady State Visual Evoked Potential (SSVEP). SSVEPs generate a periodic electrical potential difference induced by repetitive visual stimulation, typically at frequencies above $6 \mathrm{~Hz}$. The frequency range associated with SSVEP generally comprises the fundamental frequency of the visual stimulus, as well as its harmonics (Lin, et al., 20075; Zhang et al., 2014). In addition, $\mathrm{BCl}$ systems based on SSVEP require few EEG channels for their development (Lalor, et al., 2004; Tello,et al., 2015; Valbuena,et al., 2007; Wang \& Jung, 2010).

One of the main areas of study of signal processing in $\mathrm{BCl}$ systems is the measure extraction, that consists in finding the characteristic elements of the data signal, that is, to determine a characteristic vector from a regular vector. A characteristic is a distinctive measure or structural component or a pattern extracted from a data segment. The measure extraction scheme is designed to choose the characteristics or information that is most important for the classification exercise (Al-Fahoum \& Al-Fraihat, 2014). To obtain a characteristic vector, the signal will be decomposed into groups of frequencies (brain rhythms), each group represent a vector.

In this work population-based algorithms will be introduced and their possible applications in neuroscience are presented. Particle Swarm Optimization (PSO), Ant Colony Optimization (ACO), Genetic Algorithm (GA) and Differential Evolution (DE) will be implemented to measure its behavior in the feature extraction process of $\mathrm{BCl}$ based SSVEP.

In order to evaluate the behavior of algorithms, Power Spectral Density (PSD), which shows the average power distribution as a function of frequency, as well as the Spectral Coherence (SC) that measures the correlation between two signals as a function of the frequency was implemented. 


\section{Materials and Methods}

\subsection{Experimentation}

In the present work, the inverse pattern stimulus test is used where graphical patterns are represented on a screen by oscillatory alternation. The experiment consists of at least two patterns that alternate in a specified number of alternations per second. Patterns are usually colored in black and white, as shown on Figure 1; where chessboard patterns are used. All repetitive visual stimuli have diverse properties, such as frequency, color and contrast. The stimulus of the chessboard is characterized by the subtended visual angle of each mosaic (spatial frequency), the number of changes per second, and the average luminance, the size of the board and the contrast of the pattern. Individual graphic stimuli provoke an SSVEP response to the frequency during a complete cycle (two alternations), while the actual pattern of inversion stimuli causes an SSVEP response to the frequency of an alternation (Zhu, et al., 2010).

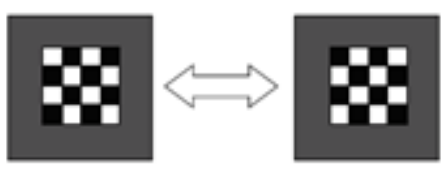

Figure 1. Inverse pattern stimuli, chessboards.

Bakardjian, Tanaka, and Cichocki (2010) used a single chessboard, which is shown for three sequential alternating frequencies $(8,14$ and $28 \mathrm{~Hz}$ ), covering each of the three SSVEP response regions (low, medium and high Frequencies) (Regan, 1977). Six replicates of assay were used for each frequency. Each trial consisted of $5 \mathrm{~s}$ basal (screen black) and $15 \mathrm{~s}$ stimulation, the SSVEP ONSET point is at second 5 from beginning of the data and the SSVEP OFFSET point is at second 20 from beginning of the data (Bakardjian, et al., 2010).

\subsection{Data Recording}

EEG signals were obtained under the experimental design of the Brain Science Institute, Laboratory for Advanced Brain Signal Processing (RIKEN), using the 128-channel BIOSEMI system with a sampling frequency of $256 \mathrm{~Hz}$ (Bakardjian, et al., 2010). For the visualization of the experiment, a vertical refresh rate monitor of $170 \mathrm{~Hz}$ was used and the users were located to a distance of $90 \mathrm{~cm}$ of the monitor. The signals used in the present work were acquired from the SSVEP database provided by RIKEN and Dr. Hovagim Bakardjian (Bakardjian, et al., 2010; RIKEN).

\subsection{Particle Swarm Optimization (PSO)}

PSO was developed by Kennedy and Eberhart (1995), as an optimization method of nonlinear functions in continuous and discrete spaces. PSO is a computational method that optimizes a problem by iteratively trying to improve a candidate solution with regard to a given measure of quality (Mojžíš, et al., 2014). Based on the simulation of a simple social model of the displacement of schools or flocks as shown on Figure 2. In a PSO system, the search is performed using a population of particles that correspond to the individuals, each of which represents a candidate solution to the problem. Particles change their state by "flying" through the search space until a relatively stable state has been found. Figure 3 shows the particle optimization process (Muñoz, et al., 2008). PSO has been used for the development of different areas of $\mathrm{BCl}$ systems: in signal processing for measure selection, (Atyabi, et al., 2013; Atyabi, et al., 2012; Yu, et al., 2012); EEG signals classification (Cinar \& Sahin, 2013; Escalona-Vargas, et al., 2014; Rajaguru \& Prabhakar, 
Santiago M. Fernandez-Fraga, Marco Antonio Aceves-Fernandez, José Emilio Vargas Soto, Juan Manuel Ramos Arreguín; Population-Based Algorithms Applied to Brain-Computer Interfaces upon Steady-State Visual Evoked

2016) as adaptive signal filter (Ahirwal, et al., 2014. Ahirwal, et al., 2012; Yu, et al., 2009) feature recognition of EEG (Ma, et al., 2016). PSO as a static classifier in conjunction with neural networks (Sun, et al., 2009) and as dynamic classifier (Hema, et al., 2008).

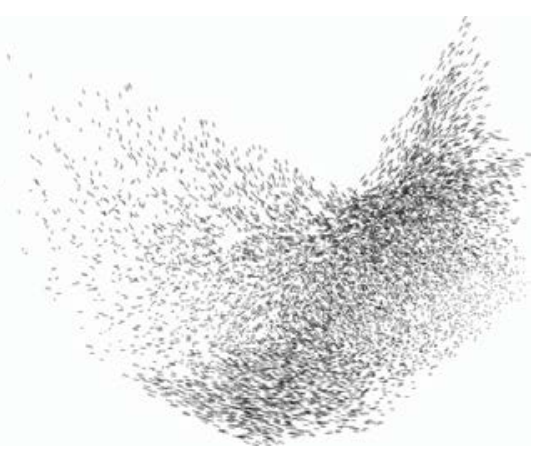

Figure 2. Representation of a swarm of particles.

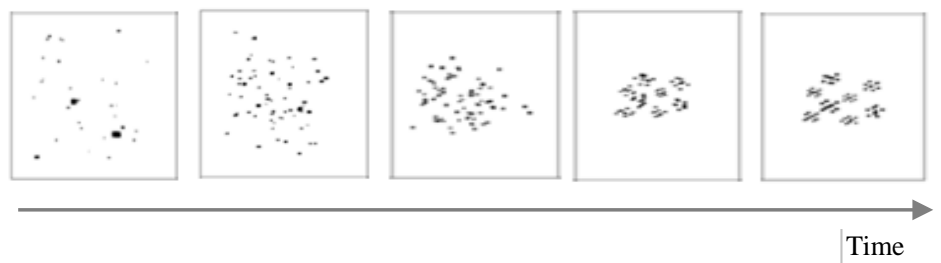

Figure 3. Particle optimization process (Ab Wahab et al., 2015).

Consider each EEG signal as a time series $\mathrm{X}(\mathrm{n})=\left(\mathrm{x}_{1}, \mathrm{x}_{2}, \ldots \mathrm{x}_{\mathrm{N}}\right)$,, with a length $\mathrm{N}$. In PSO the i-th particle is treated as a point within an $\mathrm{N}$-dimensional space, represented by $\mathrm{X}_{\mathrm{i}}=\left(\mathrm{x}_{\mathrm{i} 1}, \mathrm{x}_{\mathrm{i} 2}, \ldots, \mathrm{x}_{\mathrm{iN}}\right)$. The best position found by the particle, this means, the one where the best value in the cost function was obtained, is represented as $p_{i}=\left(p_{i 1}, p_{i 2}, \ldots, p_{i N}\right)$. The best position found by the total population is represented by $g$. The rate of change of position (velocity) for a particle $i$ is represented as $v_{i}=\left(v_{i 1}, v_{i 2}, \ldots, v_{i N}\right)$. The particles are manipulated according to equations (1) and (2), where $c_{1}$ and $c_{2}$ are two positive constants, $R_{1}$ and $R_{2}$ are two random numbers in the range of [0 1], and $w$ is the inertial weight (Ab Wahab et al., 2015).

$$
\begin{gathered}
v_{\text {in }}(t+1)=w_{\text {in }}(t)+c_{1} R_{1}\left(p_{\text {in }}-x_{\text {in }}(t)\right)+c_{2} R_{2}\left(p_{\text {gn }}-x_{\text {in }}(t)\right) \\
x_{\text {in }}(t+1)=x_{\text {in }}(t)+v_{\text {in }}(t+1)
\end{gathered}
$$

Eq. (1) calculates the new velocity of the particle in relation to its previous speed and the distances from its current position to its best position and the best position within the group. Then, the particle moves to a new position according to Eq. (2). The inertial weight w, formulated by Shi and Eberhart (1998), is used to control the impact of the previous velocities on the current velocity, influencing the change between the global (wide range) or local (short range) particles (Muñoz, et al., 2008).

A feature of the PSO algorithm is that its global and local exploration capabilities can be easily balanced by adjusting the relative influence of best local solution and global solution during speed update (Merkle 
\& Middendorf, 2008). A PSO system combines a "socially only" model, which suggests that individuals ignore their own experience and adjust their knowledge according to the successful beliefs of individuals in the neighborhood; and a "cognitive-only" model, which treats individuals as isolated beings (Muñoz, et al., 2008). The influence of the best personal position is considered as the cognitive aspect of the behavior of the particles, while the influence of the best overall position is considered as the social aspect.

\subsection{Ant Colony Optimization (ACO)}

Dorigo and his colleagues firstly developed ACO in the early 1990s to solve the hard combinatorial optimization problems such as the Traveling Agent Problem (TSP) (Huang, et al., 2012; Chandra \& Baskaran 2011), obtaining good enough solutions in a reasonable amount of computation time (Kanan \& Faez, 2008).

ACO algorithms are a type of metaheuristic that simulates the social behavior of insect swarms to solve optimization problems and are inspired by the real "foraging" behavior type of colonies of ants. (Das, et al., 2008). When they find a food source, the ants deposit a pheromone to mark the path. Pheromone is an odorous substance that is used as an indirect means of communication. The amount of pheromone deposited depends on the distance, quantity and quality of the food source. If an isolated and random ant detects the established pheromone, it is very likely that it decides to follow that route. This ant will reinforce the trail of pheromones of that specific route by depositing a quantity of pheromone itself. Therefore, it is more attractive to follow the path that has been used by more ants (Figure 4) (Khushaba,ert al., 2008).

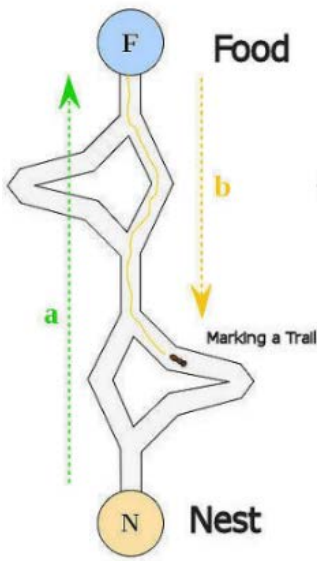

(a)

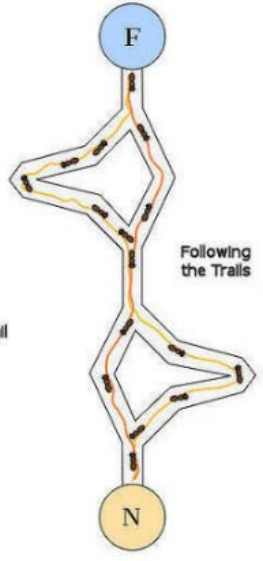

(b)

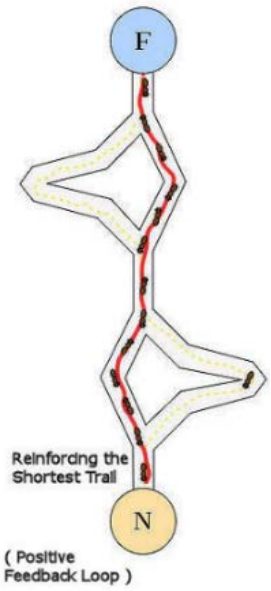

(c)

Figure 4. Ant's behavior process. a denotes the feed search direction and $b$ is the returning nest direction. (a)

Shows the early process where the ants begin to find a path between the nest and the source and the pheromone deposit in the path. (b) Shows an intermediate process in which the ants crossed all the possible ways until arriving at the food increasing the deposit of pheromone in the route. (c) Shows that most ants choose the path with the highest pheromone concentration. 
Santiago M. Fernandez-Fraga, Marco Antonio Aceves-Fernandez, José Emilio Vargas Soto, Juan Manuel Ramos Arreguín; Population-Based Algorithms Applied to Brain-Computer Interfaces upon Steady-State Visual Evoked Potentials, Transactions on Machine Learning and Artificial Intelligence, Volume 7 No 2 April, (2019); pp: 1-33

The first algorithm proposed within the ACO metaheuristic was the Ants System (AS) to solve the Traveling Agent Problem (TSP) (Stützle \& Dorigo,1999; Dorigo, \& Gambardella, 1997; Dorigo, et al., 2006; Gan, et al., 2010; Aggarwal \& Saroj, 2012; Yun, et al., 2013). The objective of this problem is to find the shortest route that allows visiting a set of cities, where the distance between them is known, and these cities are visited only once. Formally, the objective is to find a Hamiltonian path of minimum length in a fully connected graph (Dorigo, et al., 2006).

AS main characteristic is that, each $\mathrm{m}$ ant makes a complete path of the graph according to the probabilistic rule of passing from one node to another. The pheromone values are updated at each level of iteration by all the $m$ ants in the problem space (Adubi \& Misra, September 2014). In each iteration, pheromone values are updated for all $\mathrm{m}$ ants that have generated a solution in the same iteration (Dorigo, et al., 2006). The pheromone $\tau_{\mathrm{ij}}$, associated with the edge joining cities $\mathrm{i}$ and $\mathrm{j}$, is updated as follows:

$$
\tau_{\mathrm{ij}}=(1-\rho) \tau_{\mathrm{ij}}+\sum_{\mathrm{k}=1}^{\mathrm{m}} \Delta \tau_{\mathrm{ij}}^{\mathrm{k}} \quad \forall(\mathrm{i}, \mathrm{j}) \in \mathrm{L}
$$

where $0<\rho \leq 1$ is the evaporation rate, $m$ is the number of ants, $\Delta \tau_{i j}^{k}$ is the amount of pheromone deposited in the $\operatorname{arc}(i, j)$ by the ant $k$ and $L$ the set of arcs between cities.

$$
\Delta \tau_{\mathrm{ij}}^{\mathrm{k}}=\left\{\begin{array}{cc}
\frac{\mathrm{Q}}{\mathrm{L}_{\mathrm{k}}} & \text { if }(\mathrm{i}, \mathrm{j}) \in \mathrm{L}_{\mathrm{k}} \\
0 & \text { otherwise }
\end{array}\right.
$$

$\mathrm{L}_{\mathrm{k}}$ representing the length of the trail constructed and $\mathrm{Q}$ as a constant of generation of pheromone (Khushaba,ert al., 2008; Dorigo, \& Gambardella; 1997; Yun, et al., 2013; Adubi \& Misra, 2014; ManceraGalván, et al., 2015).

The general structure of ACO algorithms can be described Figure 5. 


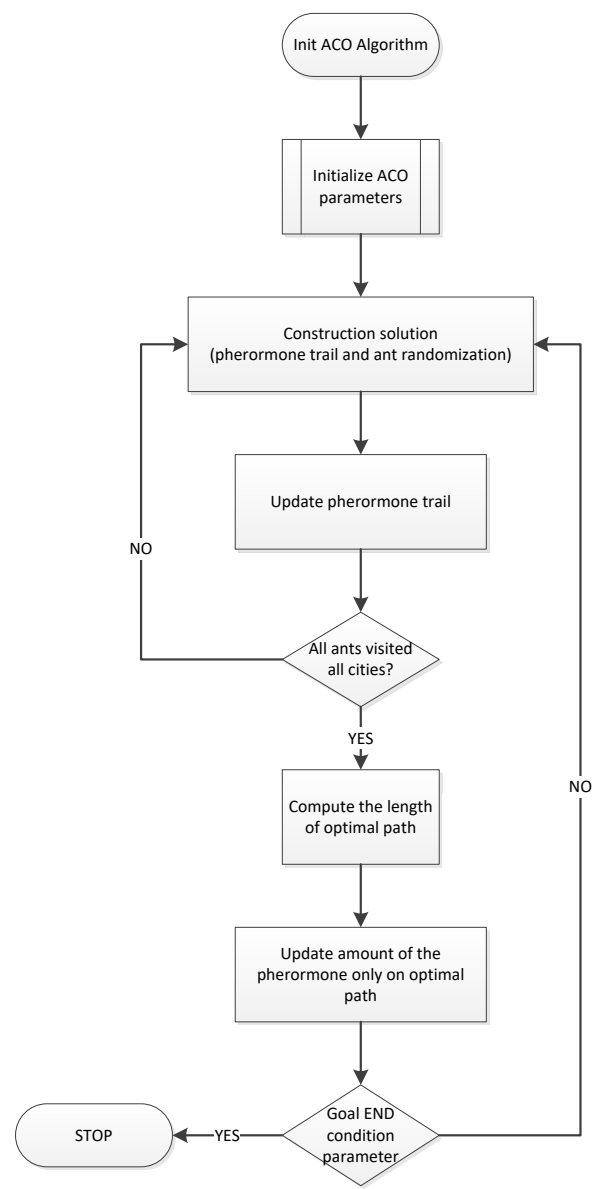

Figure 5. Ant Colony Optimization flow chart.

\subsection{Genetic Algorithms (GA)}

The GA are based on biological evolution and are the oldest and most used search algorithms. The term GA was first published by Bagley (1967), who designed algorithms to look for sets of parameters in game evaluation functions. However, John Holland is considered the creator of the GA; in his book, "Adaptation in Natural and Artificial Systems" (1975) presented the theoretical bases of Genetic Algorithms (Rodríguez-Piñero, 2003).

The optimal global solution of GA is obtained by moving from an old population of individuals (solutions or chromosomes) that uses genetic operators (crossing and mutation) to obtain a new population. Each individual within the population receives a fitness value through an evaluation function. The basic optimization strategy is the selection of the best individuals, based on their fitness value, to generate better individuals in the next generation (Huang, et al., 2012; Whitley, 1994; Kołodziej,et al., 2011).

A typical GA involves four main steps: assessment of fitness, selection, crossover and mutation of a new population (Ahirwal, et al., 2014). The aptitude assessment determines that individuals are better, based on the parameters defined in the fitness function, and that they will become part of the next generation. The selection process is randomized to diversify possible solutions to the system. The crossover operation is defined as 
Santiago M. Fernandez-Fraga, Marco Antonio Aceves-Fernandez, José Emilio Vargas Soto, Juan Manuel Ramos

Arreguín; Population-Based Algorithms Applied to Brain-Computer Interfaces upon Steady-State Visual Evoked

Potentials, Transactions on Machine Learning and Artificial Intelligence, Volume 7 No 2 April, (2019); pp: 1-33

$$
\mathrm{C}_{\mathrm{i}}^{\text {gen+1 }}=\mathrm{aC}_{\mathrm{i}}^{\text {gen }}+(1-\mathrm{a}) \mathrm{C}_{\mathrm{j}}^{\text {gen }} \text { and } \mathrm{C}_{\mathrm{j}}^{\text {gen+1 }}=(1-\mathrm{a}) \mathrm{C}_{\mathrm{i}}^{\text {gen }}+\mathrm{aC}_{\mathrm{j}}^{\text {gen }}
$$

where $C_{i}^{\text {gen }}$ and $C_{j}^{\text {gen }}$ are two randomly selected chromosomes for the crossover, $C_{i}^{\text {gen }+1}$ and $C_{j}^{\text {gen }+1}$ are the next generation of individuals which are a linear combination of their parents, $a$ is a random number in the range of [0 1]. The mutation operation involves a random alteration of an individual generating random real value, multiplied to make a random change.

The population of chromosomes is defined as $\mathrm{C}_{1}, \mathrm{C}_{2}, \ldots, \mathrm{C}_{\mathrm{N}}$ where $\mathrm{N}$ is the size of the population. After performing genetic operations such as crossover and mutation, the population size becomes $2 \times \mathrm{N}$. Among $2 \times \mathrm{N}$ values, the selection of the L-values may be done by different methods, being the "roulette wheel" selection the most popular method used. The physical fitness values after the assessment are normalized and the cumulative distribution of the normalized fitness values obtained is obtained, Figure 6 (Ahirwal, et al., 2014).

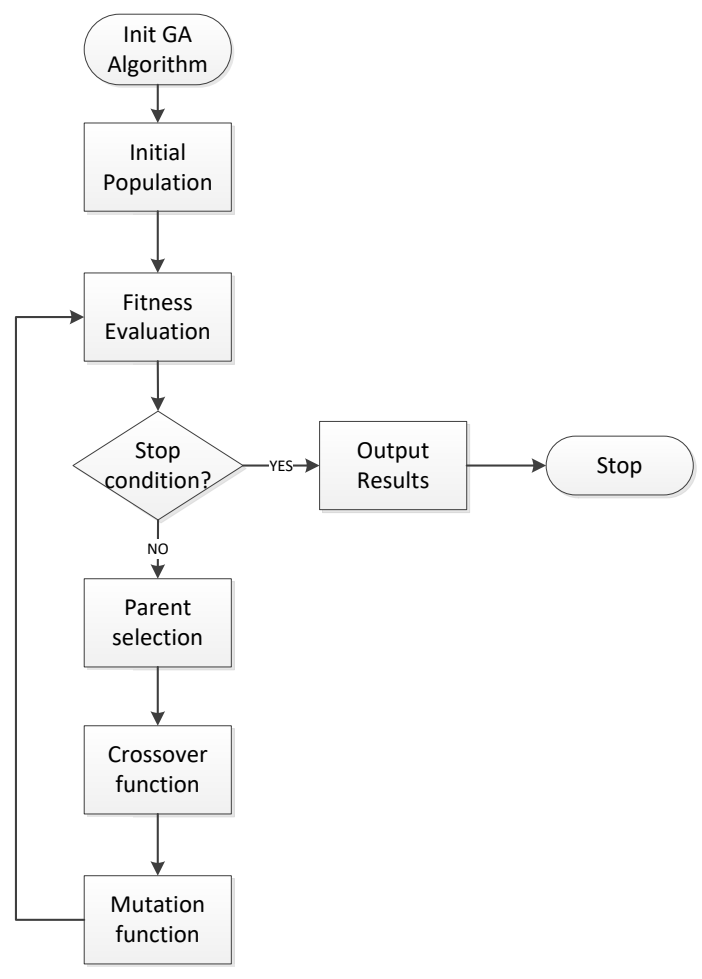

Figure 6. Genetic Algorithm flow chart.

\subsection{Differential Evolution (DE)}

The Differential Evolution (DE) is an optimization method capable of handling non-differentiable, nonlinear and multimodal objective functions. Is a population-based and parallel direct search method, which is used to approximate the global optimal solution (Jiang, et al., 2013). A simple, parallel, and direct search has good convergence properties and rapid implementation (Khushaba, et al., 2008; Lian, et al., 2013). Storn and Price introduced this algorithm in 1997 (Storn \& Price, 1997). 
Based on evolutionary metaheuristic techniques, similar in the operation of a GA, first generate a population of $\mathrm{ND}$-dimensional vectors $\mathrm{X}_{\mathrm{i}, \mathrm{G}}, \mathrm{i}=1,2, \ldots, \mathrm{N}$ and $\mathrm{G}$ denotes the current generation. Each vector contains a randomly selected potential solution (a random location in the search space). The mutation for a "target" vector $\mathrm{X}_{\mathrm{i}, \mathrm{G}}$ is defined as

$$
\mathrm{V}_{\mathrm{i}, \mathrm{G}+1}=\mathrm{X}_{\mathrm{r} 1, \mathrm{G}}+\mathrm{F}\left(\mathrm{X}_{\mathrm{r} 2, \mathrm{G}}-\mathrm{X}_{\mathrm{r} 3, \mathrm{G}}\right)
$$

where $\mathrm{X}_{\mathrm{r} 1, \mathrm{G}}, \mathrm{X}_{\mathrm{r} 2, \mathrm{G}}, \mathrm{X}_{\mathrm{r} 3, \mathrm{G}} \mid \mathrm{r} 1 \neq \mathrm{r} 2 \neq \mathrm{r} 3 \neq \mathrm{i}$ are random population vectors and $\mathrm{F}$ is a constant weighting factor, $\mathrm{F} \in\left[\begin{array}{ll}0 & 2\end{array}\right]$. The vector $\mathrm{V}_{\mathrm{i}, \mathrm{G}+1}$ is called the "donor" vector.

For the crossover operation, a crossover scheme is applied to the "target" vector $\mathrm{X}_{\mathrm{i}, \mathrm{G}}$ and the "donor" vector $\mathrm{V}_{\mathrm{i}, \mathrm{G}}$ to produce the vector "trail" $\mathrm{U}_{\mathrm{i}, \mathrm{G}+1}$ defined by

$$
U_{j, i, G+1}=\left\{\begin{array}{l}
V_{j, i, G+1} i f R_{j, i} \leq C R \vee j=I_{\text {rand }} \\
X_{j, i, G} i_{j, i}>C R \wedge j \neq I_{\text {rand }}
\end{array}\right.
$$

where $i=1,2, \ldots, N, j=1,2, \ldots, D$. CR is a crossover constant between $[01], R_{j}$ is a random real number between [0 1] and $I_{\text {rand }}$ is a random integer between $[1,2, \ldots, D]$ which ensures $V_{i, G+1} \neq X_{i, G}$. For the selection process, we defined that

$$
\mathrm{X}_{\mathrm{i}, \mathrm{G}+1}=\left\{\begin{array}{cc}
\mathrm{U}_{\mathrm{i}, \mathrm{G}+1} \mathrm{iff}\left(\mathrm{U}_{\mathrm{i}, \mathrm{G}+1}\right) \leq \mathrm{f}\left(\mathrm{X}_{\mathrm{i}, \mathrm{G}}\right) \\
\mathrm{X}_{\mathrm{i}, \mathrm{G}} & \text { othercase }
\end{array}\right.
$$

where $\mathrm{f}(\cdot)$ evaluates the fitness of the candidate vector to meet the requirements of the desired solution. DE algorithm is interactive until some stop criterion is met (Figure 7) (Ab Wahab, et al., 2015; Khushaba, et al., 2008; Daly, I., et al., 2011).
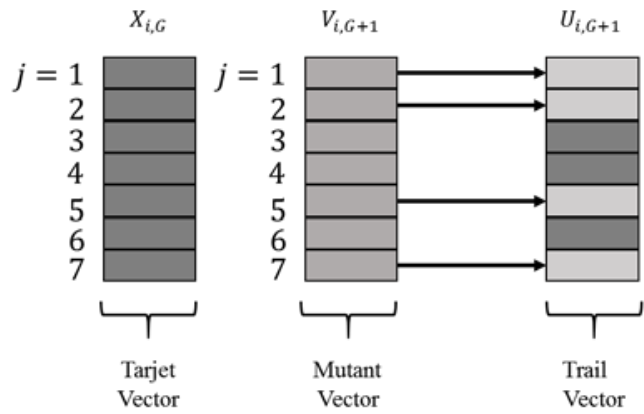

$j=1$

2
3

4

5

6
7

Figure 7. Crossing process of the DE (Ab Wahab, et al., 2015).

\subsection{Spectral Coherence (SC)}

Spectral Coherence (CS) measures the correlation between two signals as a function of frequency and similarity between them. The coherence is a quadratic correlation coefficient that estimates the relative 
Santiago M. Fernandez-Fraga, Marco Antonio Aceves-Fernandez, José Emilio Vargas Soto, Juan Manuel Ramos Arreguín; Population-Based Algorithms Applied to Brain-Computer Interfaces upon Steady-State Visual Evoked

Potentials, Transactions on Machine Learning and Artificial Intelligence, Volume 7 No 2 April, (2019); pp: 1-33 amplitude and phase consistency between a pair of signals $\mathrm{x}(\mathrm{t})$ and $\mathrm{y}(\mathrm{t})$ in each frequency band. When the coherence is equal to 1 , it is considered that the signal $\mathrm{x}(\mathrm{t})$ corresponds totally to the signal $\mathrm{y}(\mathrm{t})$, that is, they are equal; when coherence is 0 indicates that the corresponding frequency components of both signals are uncorrelated; any other value between [0 1] represents the correlation between both signals (Esqueda Elizondo et al., 2016).

The spectral coherence is also one of the most used methods for the analysis of the coordination between different brain signal derivations (Tauscher et al., 1996 and Astolfi et al., 2005. Used especially in event potentials (Weiss et al., 1996; Tauscher et al., 1996, 1997; Miranda de Sá et al., 2001; Abraham et al., 2001; Frederick et al., 2004), (Daly, l., et al., 2011).

The SC is a normalized measure of the crossed spectrum $P_{x y}(\omega)=P_{x}(\omega) P_{y}^{*}(\omega)$ of two EEG signals, $x(t)$ and $y(t)$, recorded at different sites, defined by

$$
\mathrm{SC}_{\mathrm{xy}}(\omega)=\frac{\mathrm{P}_{\mathrm{xy}}(\omega)}{\sqrt{\mathrm{P}_{\mathrm{xx}}(\omega) \mathrm{P}_{\mathrm{yy}}(\omega)}}
$$

where $\omega$ represents all the frequencies, $P_{x x}(\omega), P_{y y}(\omega)$ represent the power spectral density (PSD) of each signal and $\mathrm{P}_{\mathrm{xy}}(\omega)$ represents the crossed PSD between the two signals (Vera, 2009; Arcentales et al., 2009; Castellanos \& Makarov, 2006; Dobrea et al.,2007; Thatcher, et al., 2005; Tierra-Criollo \& Infantosi, 2001). In this contribution, the spectral coherence will be used to have a reference parameter of the characteristics of the signals optimized with respect to the original signals.

\section{Results and Discussion}

The present work, the set of real signals used was selected. In order to make comparisons, each algorithm will be executed and the results of the optimization of the subject's signal will be compared; this is, each algorithm generates an optimized signal, which is used to evaluate its behavior in the feature selection process of the $\mathrm{BCl}$ systems. Finally, a table will be presented showing the general evaluation of the presented algorithms.

Figure 8 shows the proposed methodology. $\mathrm{O} 1$ and $\mathrm{O} 2$ electrodes were selected because they are related to the visual activities, based on the international system 10-20 of 128 electrodes (Figure 9). The stimulus frequency selected for this study was $8 \mathrm{~Hz}$. We used EEGLAB V13.6.5b for the representation of EEG signal graphics. Fig. 10 represented de Original raw signal used in the present work. For the PSO, GA and DE algorithms, the signals shown in Fig. 10a are used independently $01 / 02$ for the optimization process. For ACO the signals identified as $\mathrm{O} 1$ Trial 1/Trial2 and 02 Trial1/Trial2 are used in combination, this is because the signals have the same amplitude range for a more efficient optimization process (Figure. 10a and 10b). 


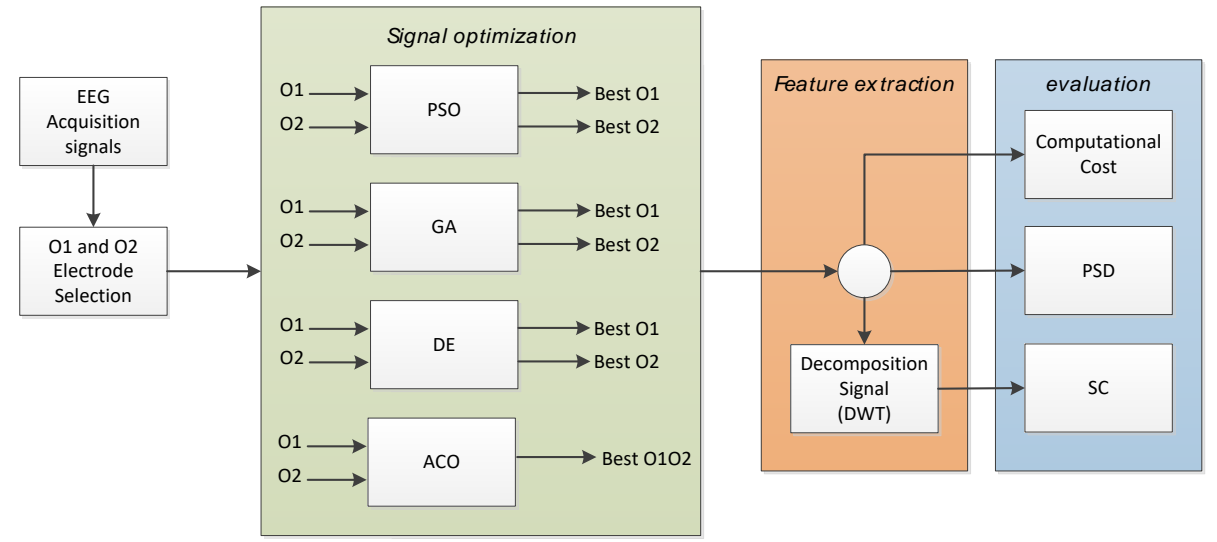

Figure 8. Methodology proposed for the present study.

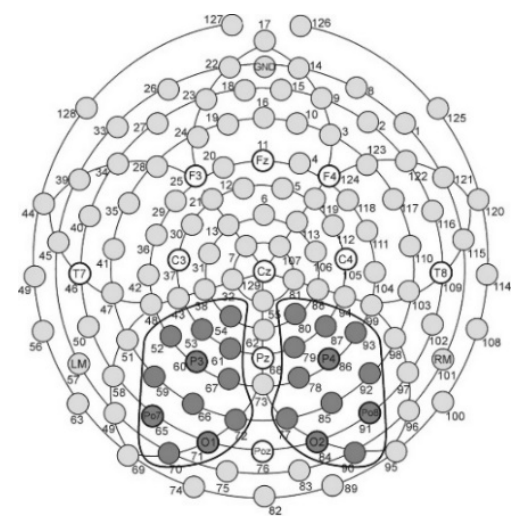

Figure 9. International System 10-20 for 128 electrodes.
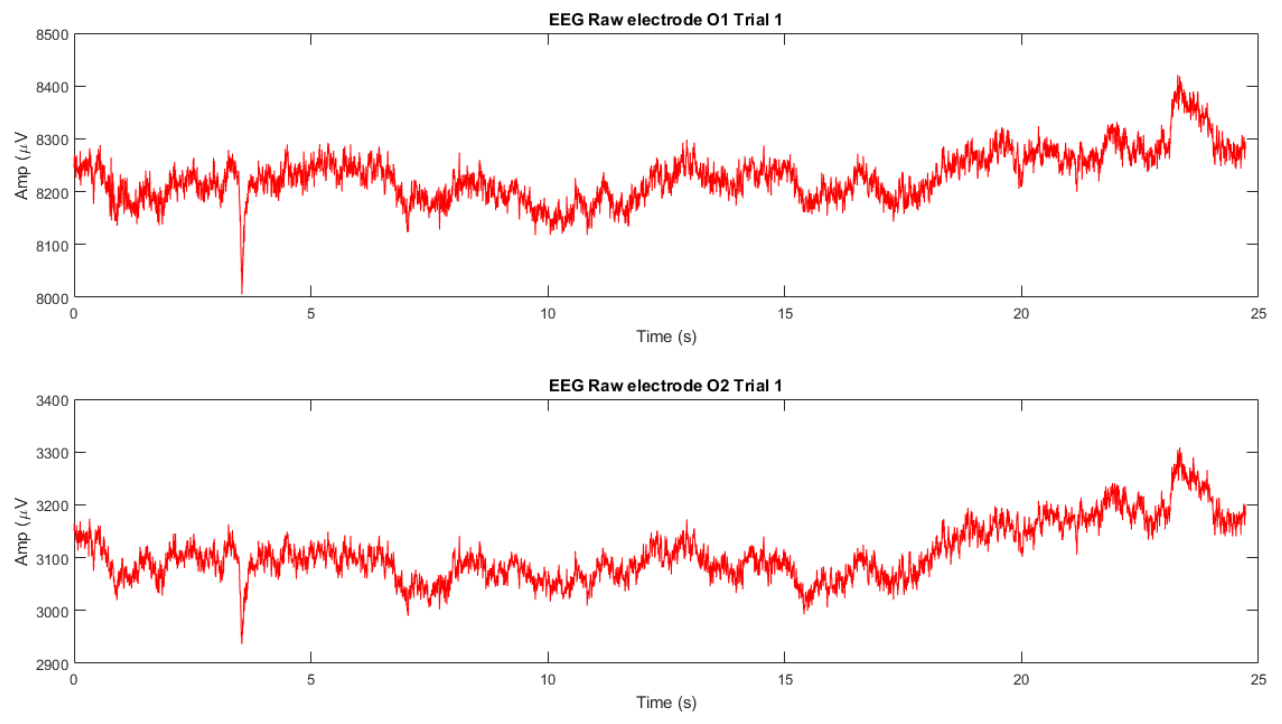

(a) 

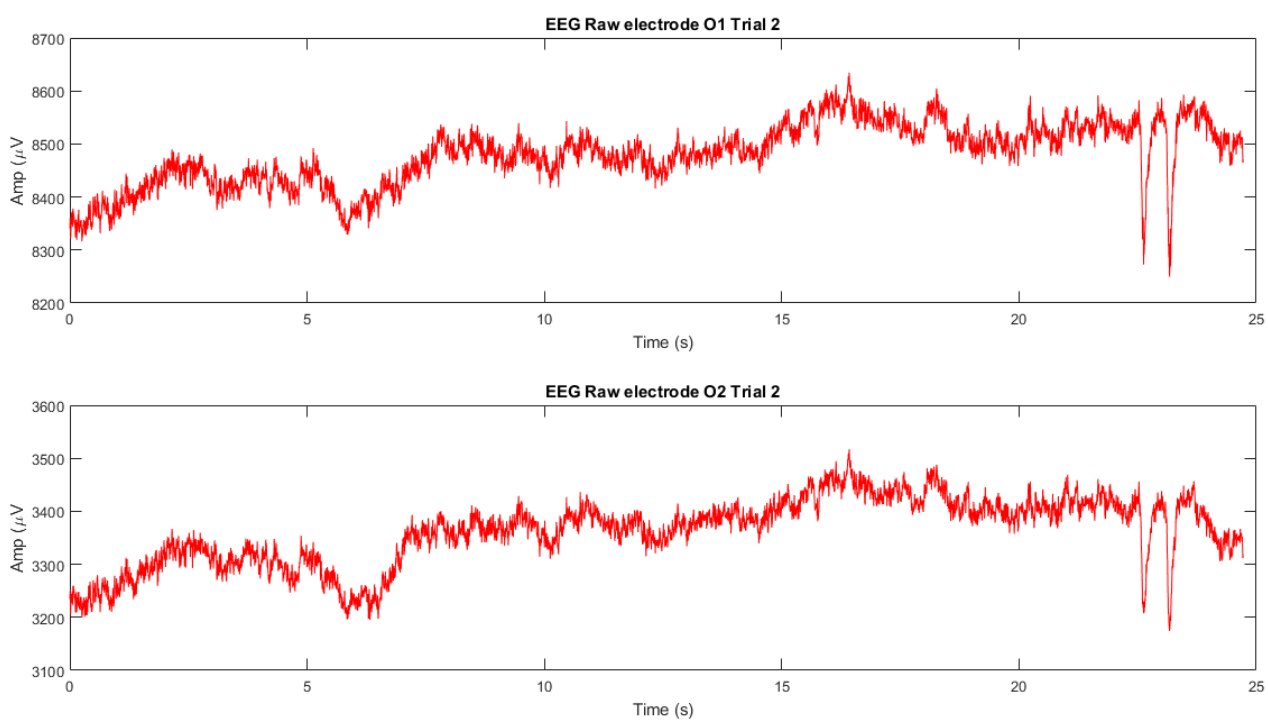

(b)

Figure 10. Original Signals. (a) Trial 1. (b) Trial 2.

The parameters to be considered for the implementation of the algorithms were: PSO $c_{1}=c_{2}=1.492$. GA crossover percentage of 0.8 and mutation rate of 0.3 . DE CR $=0.2$. ACO Q $=1, \alpha=0.5, \beta=2, \rho=$ 0.25 , ants $=10$. The number of iterations for each algorithm was 20 . An important parameter in the performance of $\mathrm{BCl}$ systems is computational cost of the optimization process.

Figure 11 shows the computational cost for the proposed algorithms. In Figure 11a we can see the convergence to the best solution during the 20 generations for each algorithm. We can observe in all cases that starting from the fourth generation the algorithms begin to obtain a stable solution. PSO shows greater changes searching for the best solution in relation to the rest of algorithms. DE showed a fast convergence to the best solution and remains constant during the longest time of the process. In the case of GA, it has some changes at the end of the process due to the very nature of the algorithm, since searched for better solutions the process of mutation can showed some difference in the best solution. For the case of ACO, the best solution arrives faster in the case of $\mathrm{O} 1$ electrodes since its signals have a smaller amplitude changes than 02 , as shown in Figure 10 and Figure $11 \mathrm{~b}$ shows the processing time of the algorithms, where it is observed that PSO is the fastest and ACO processes are the most time consuming. It is important to mention that in the case of PSO, GA and DE the time represents the optimization of both signals (01/O2), for ACO that the optimization was performed for both signals separated.

After the optimization process, the optimized signals either are obtained, which must improve the processes of the $\mathrm{BCl}$ systems, in the feature extraction or feature selection. Figures 12-15 shows, in an illustrative way, the comparison between the original signals and the signals obtained in the optimization process (BestSol) which are shown to entire duration of the test. For all figures, the similarity between the original signals and the optimized signals during the test stimulation time [5 to 20] seconds are shown. We noticed that for the optimized signals of PSO, GA and DE in $\mathrm{O} 1 \mathrm{a}$ similar behavior is observed to the original signal, but not for $\mathrm{O} 2$ where it is observed that the amplitude of the optimized signal has a greater 
variation in the amplitude in those regions where the original signal shows changes in amplitude (Figure 16). For the ACO case, we can observe that the optimization result is the same original signal O1, i.e. for ACO the 01 signal has better characteristics than the $\mathrm{O} 2$ signal. (Figure 15).

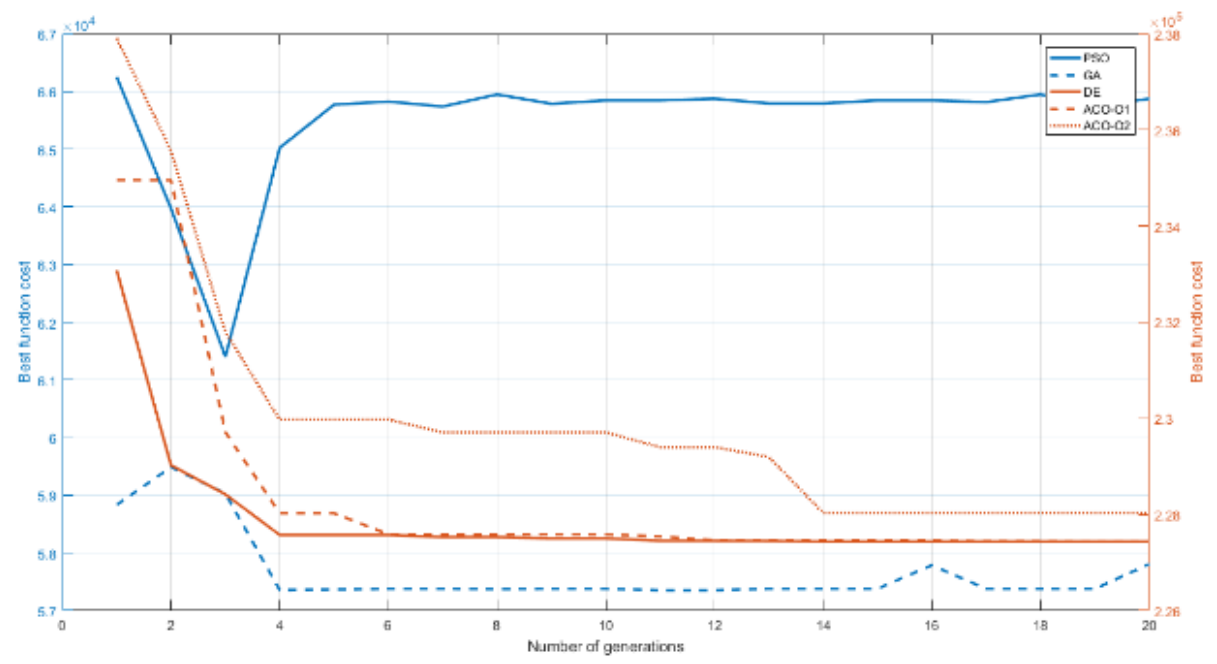

(a)

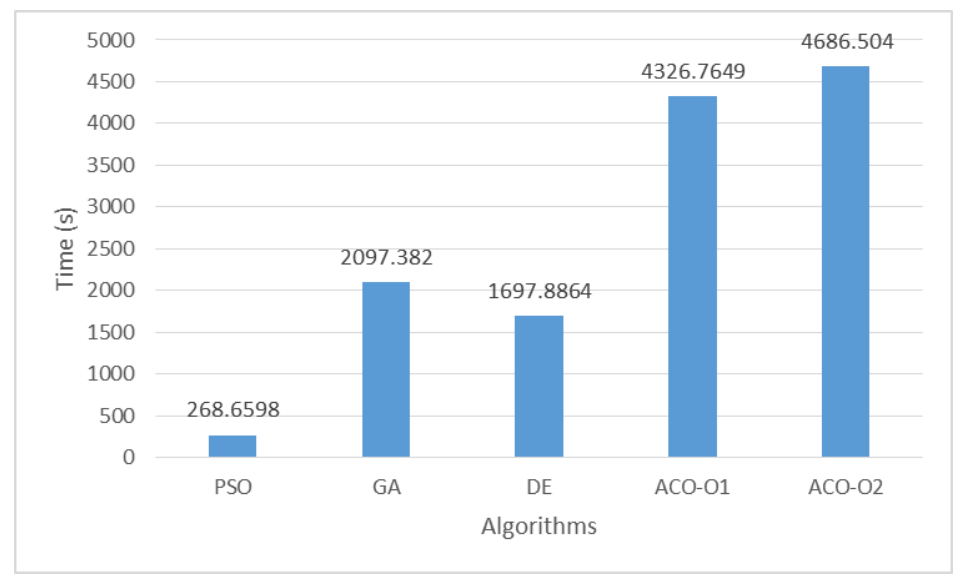

(b)

Figure 11. Algorithm performance computational cost. (a) Convergence to the best solution. (b) Total process time. 

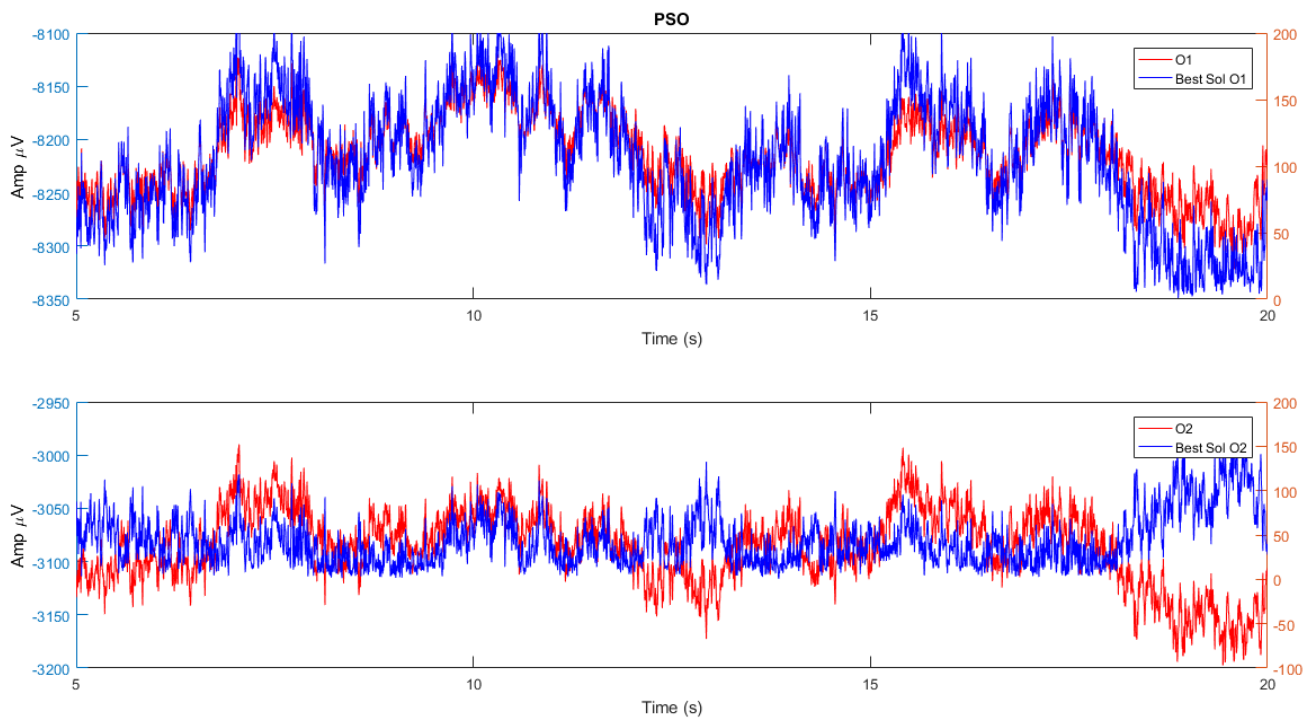

Figure 12. PSO Comparative originals signals vs optimization signals, time domain.
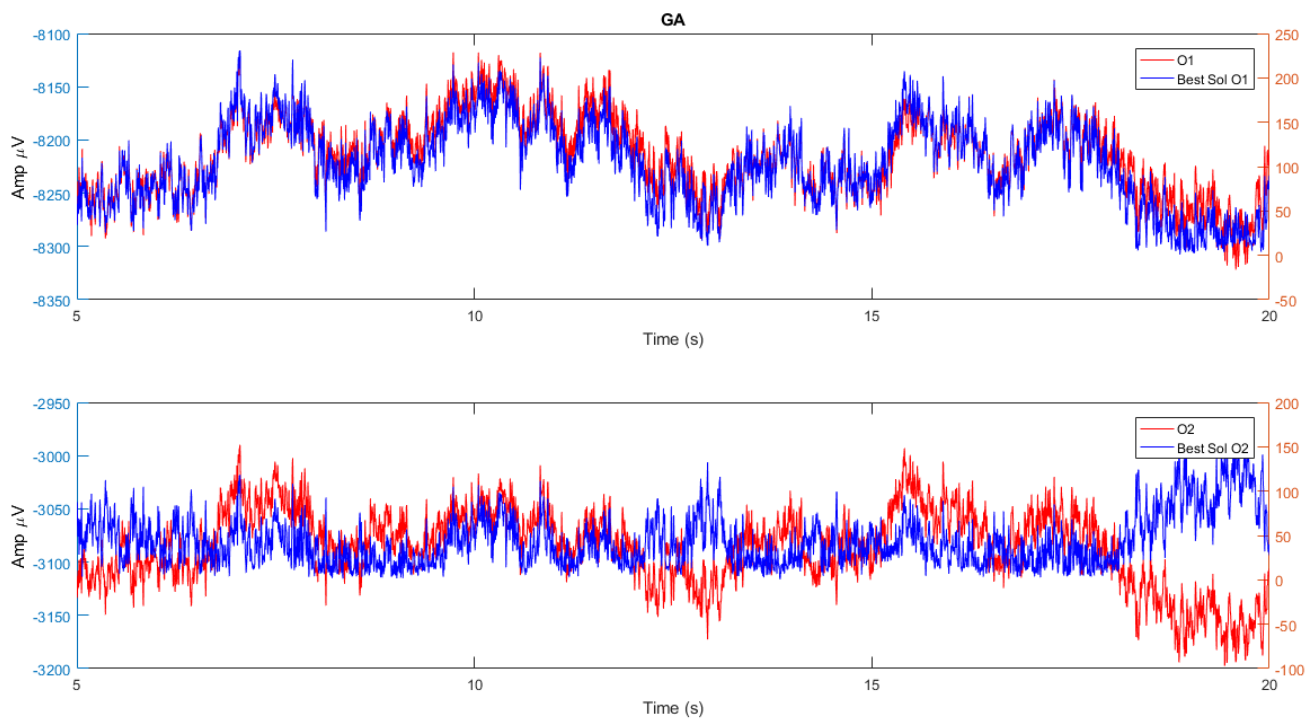

Figure 13. GA Comparative originals signals vs optimization signals, time domain. 
$\mathrm{DE}$
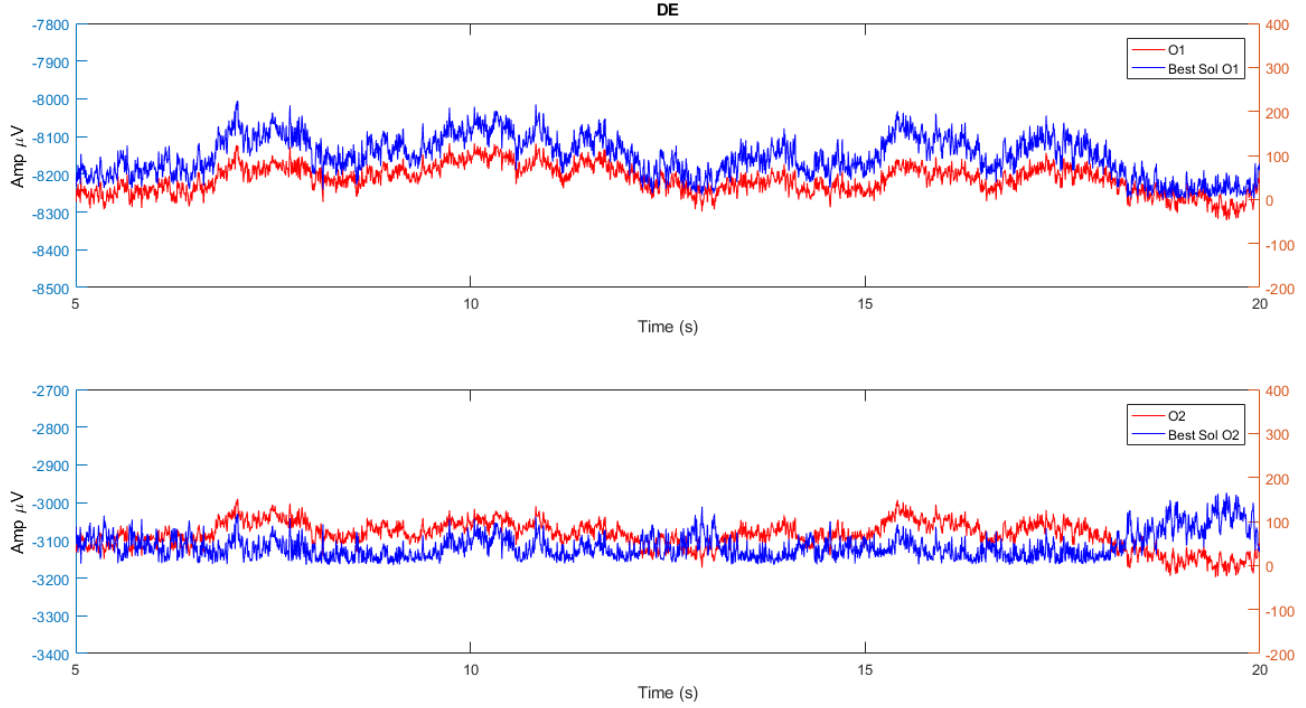

Figure 14. DE comparative originals signals vs optimization signals, time domain.
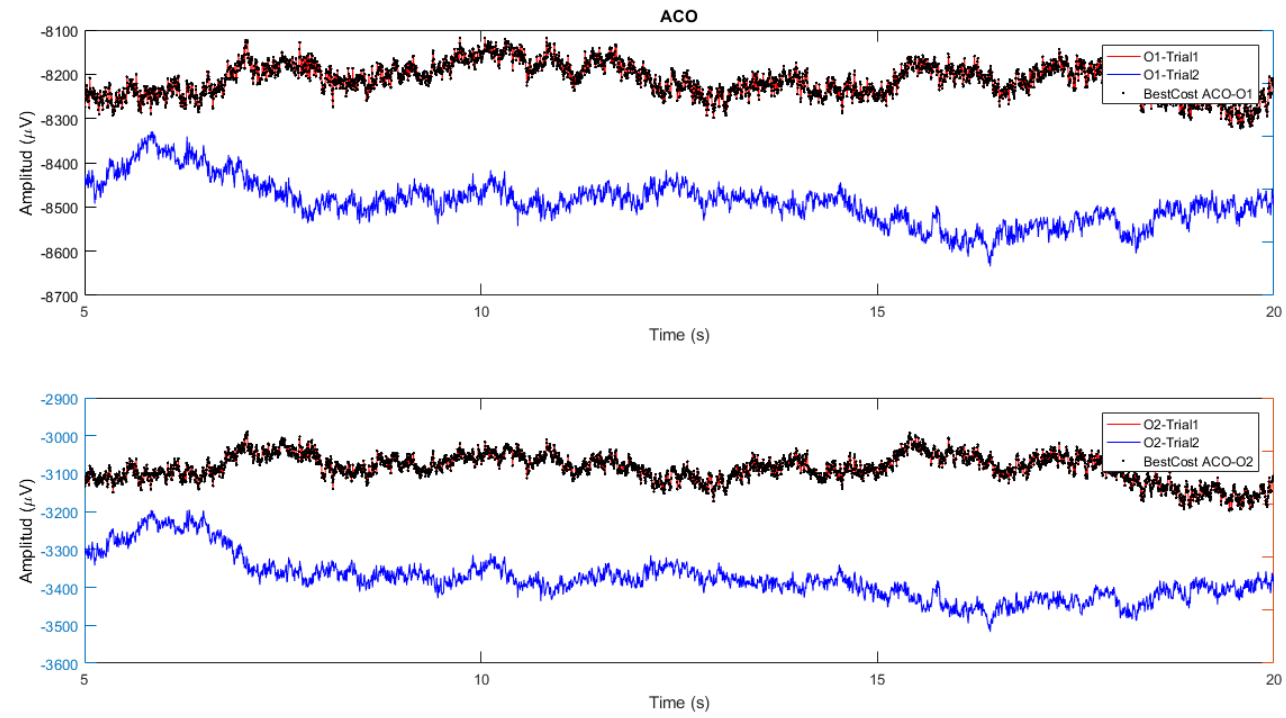

Figure 15. ACO comparative originals signals vs optimization signals, time domain. 


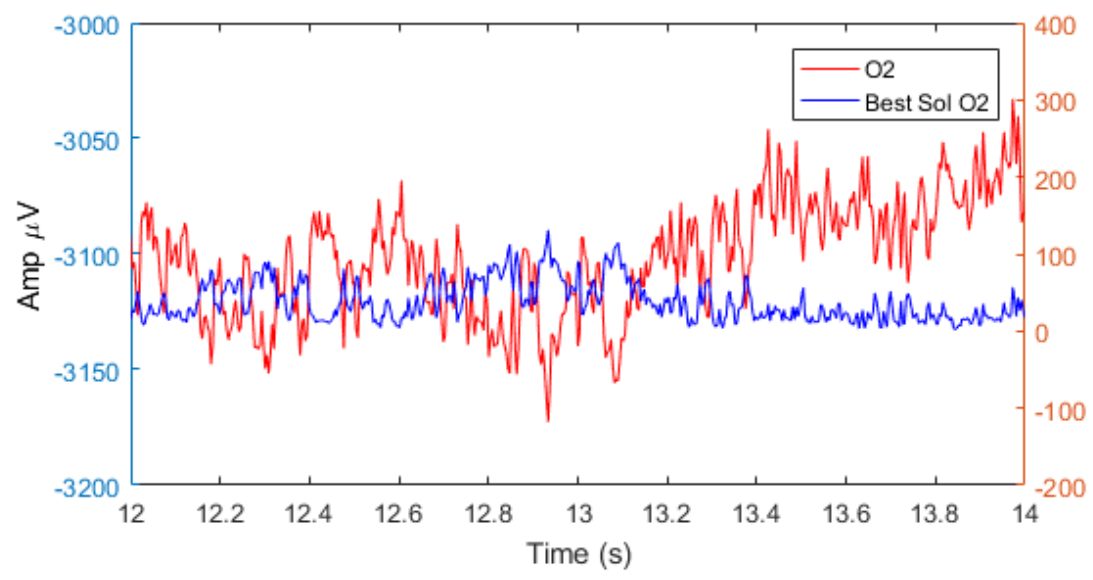

Figure 16. Details of the optimization process.

Power Spectral Density (PSD) is the frequency response of a random or periodic signal. In other words, PSD is the average power that is distributed as a function of frequency. Figure 17 shows the PSD for the original signals and the optimized signals of each electrode for the study algorithms specifically for the frequency corresponding to the stimuli performed during the test $(8 \mathrm{~Hz})$, the higher the power, the greater the probability of finding the stimulus frequency. Figures 18-21 shows, that for all activity power spectrum, the stimulus frequency is identified in every algorithm, the spectrogram plot over trial time shows an intensity energy in in case of PSO-O2 (Figure 18), GA-O2 (Figure 19), DE-O1 (Figure 20), ACO-O1 and ACO-O2 (Figure 21); the energy decreases in PSO-O1 (Figure 18), GA-O1 (Figure 19), and DE-O2 (Figure 20). With these results, we may conclude that the algorithms used in this study can be used to feature selection $\mathrm{BCl}$ process to identify de stimulus frequency.
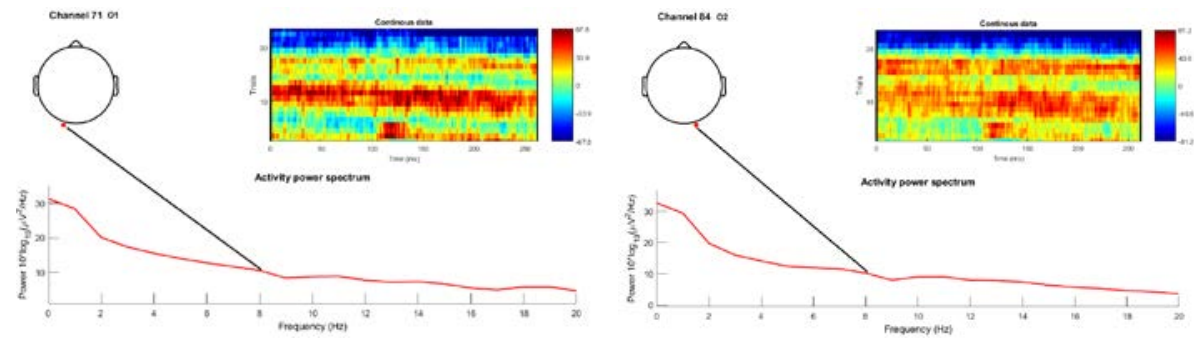

Figure 17. Raw Signals electrodes Power Spectral Density. 

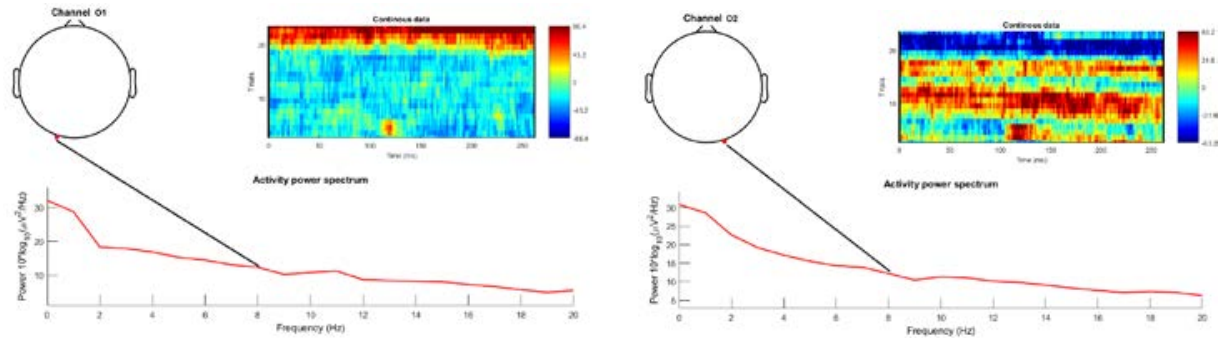

Figure 18. PSO electrodes Power Spectral Density.
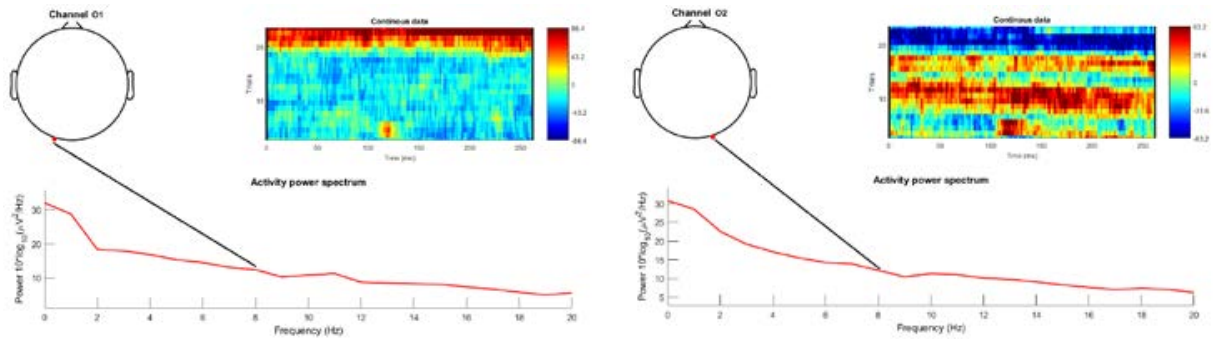

Figure 19. GA electrodes Power Spectral Density.
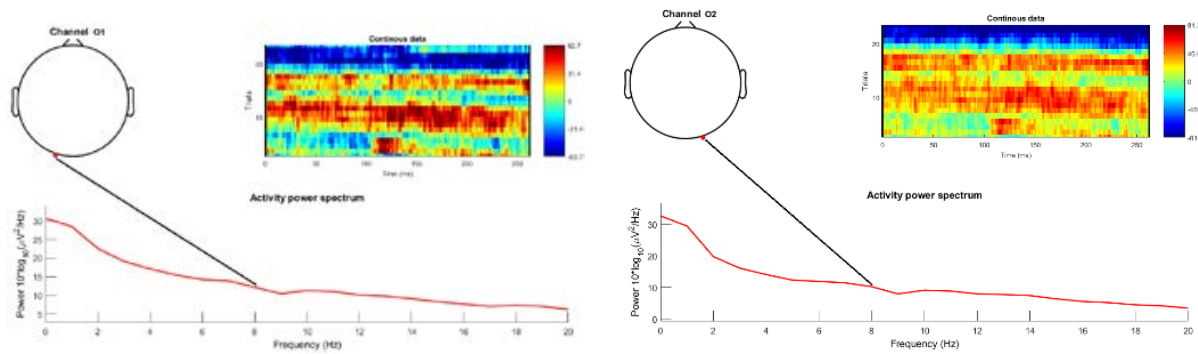

Figure 20. DE electrodes Power Spectral Density.
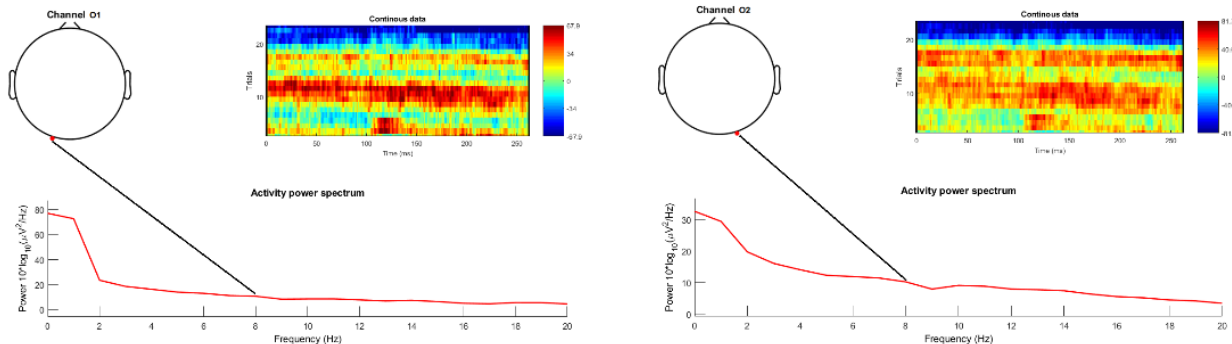

Figure 21. ACO electrodes Power Spectral Density.

Furthermore, Figures 22-24 shows frequency/time and PSD. For the case of PSO, GA and DE, the power of the signal in the range of $2-10 \mathrm{~Hz}$ is greater in the optimized signals, in the case of ACO the signal power is practically the same (Figure 24). In the range of $0-2 \mathrm{~Hz}$ the signal strength decreases for PSO, GA and DE and is conserved for ACO. For PSO-O1 the power is lower than in GA and DE (Figure 22). On the contrary, for PSO-O2 the power is higher than in GA and DE (Figure 23). In the case of ACO, the power in that range 
Santiago M. Fernandez-Fraga, Marco Antonio Aceves-Fernandez, José Emilio Vargas Soto, Juan Manuel Ramos Arreguín; Population-Based Algorithms Applied to Brain-Computer Interfaces upon Steady-State Visual Evoked Potentials, Transactions on Machine Learning and Artificial Intelligence, Volume 7 No 2 April, (2019); pp: 1-33

is practically unchanged. We can conclude that the optimization process of PSO, GA and DE concentrates more signal energy in the frequency range greater than $2 \mathrm{~Hz}$ and some features embedded in the signal in the range of less than $2 \mathrm{~Hz}$ are lost. For $\mathrm{ACO}$, which requires two sets of data for the optimization process, the optimized signals retain much more power characteristics throughout the study range.
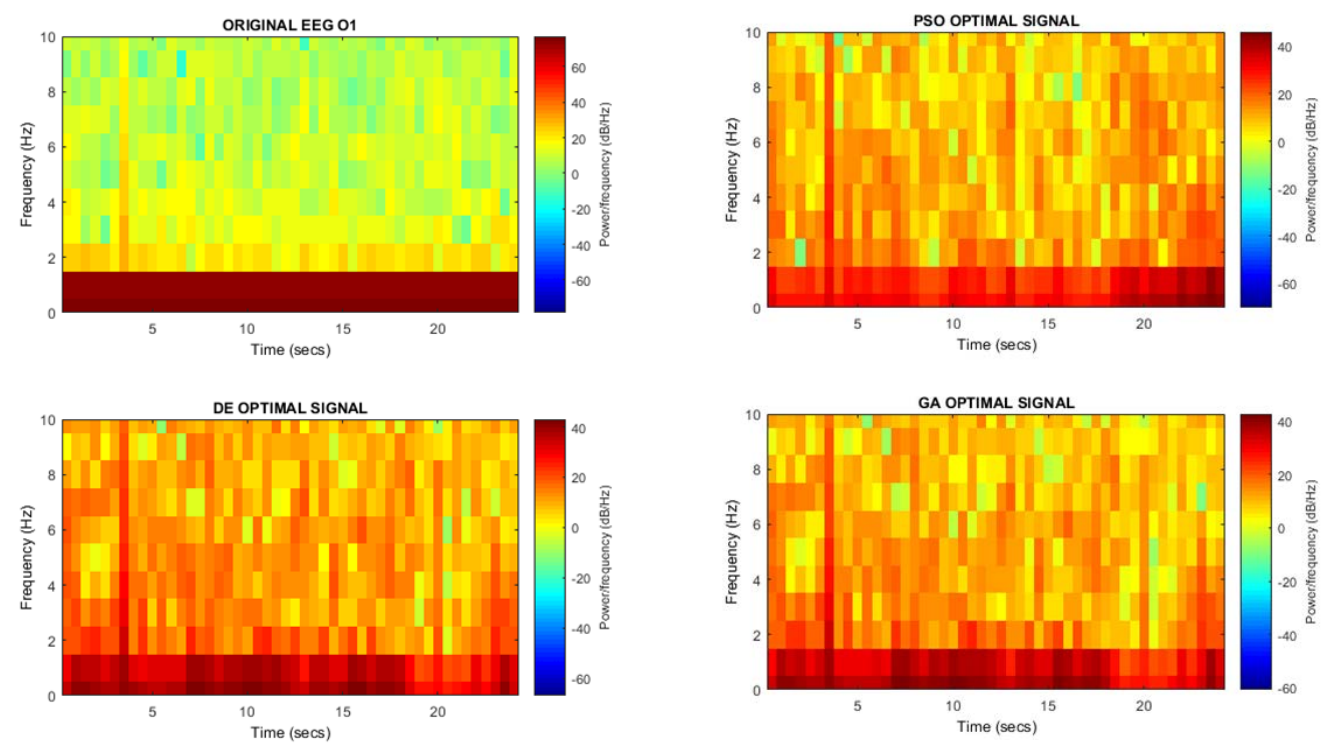

Figure 22. 01 Frequency/time PSD.
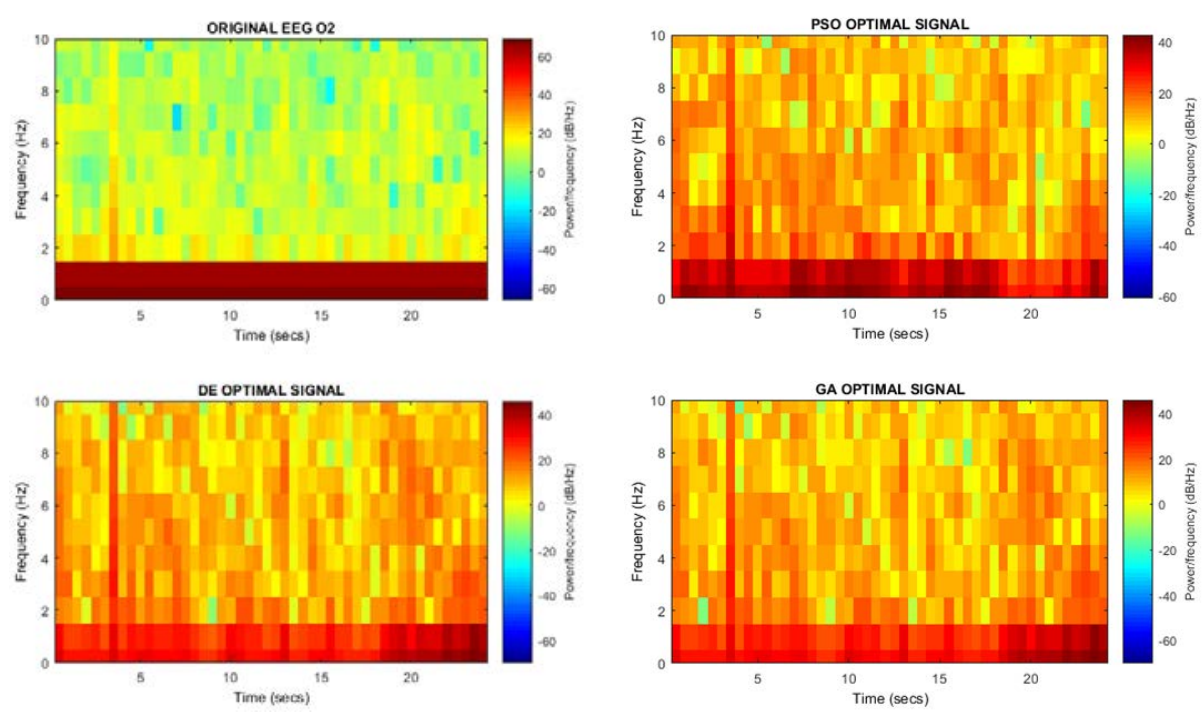

Figure 23. 02 Frequency/time PSD. 

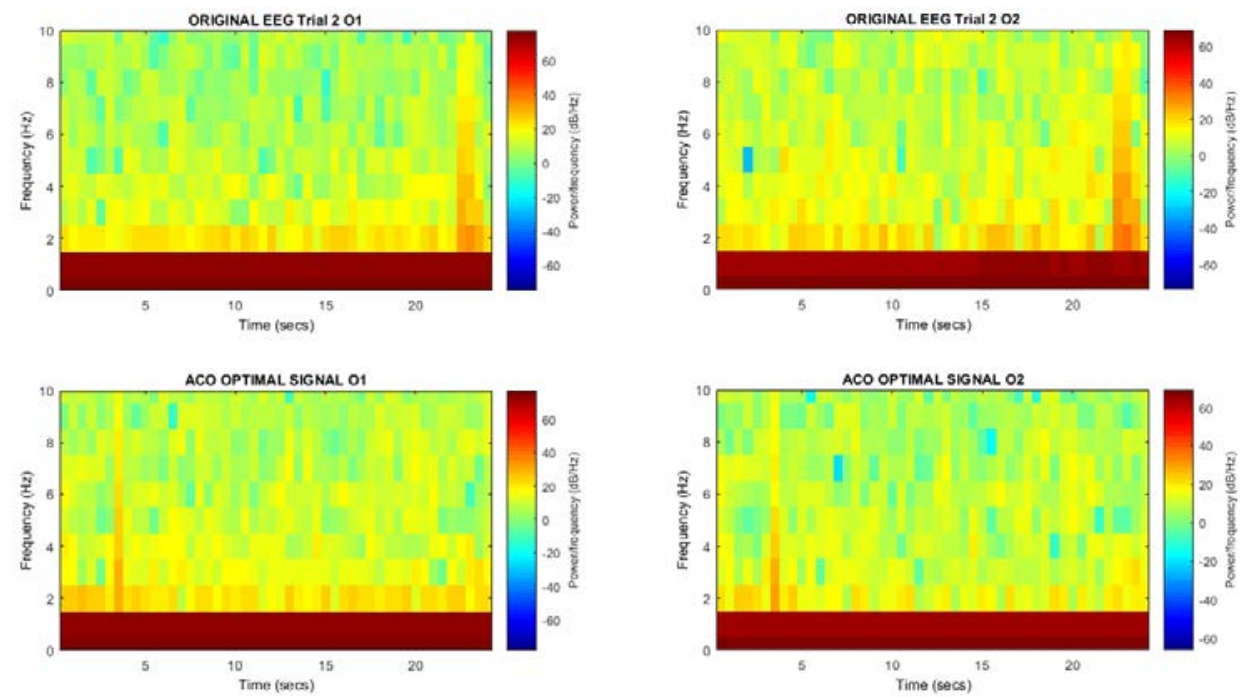

Figure 24. ACO optimal signal Frequency/time PSD.

Figure 25 shows the power of the original signals and the signals optimized in the frequency domain. We note in the original signal $\mathrm{O} 1$ that the signal strength is higher in the first harmonic and decreases considerably for harmonics 2 and 3 . In the case of the optimized signals, the power is maintained at a high level with respect to the signal original, with a high power even for DE in the 3rd harmonic (Figure 25a). In the case of $\mathrm{O} 2$, we also observed a decrease in the power signal from the first harmonic and the power is maintained at a high and similar level for the signals optimized in harmonics 1, 2 and 3 (Figure 25b). In addition, we can observe that in Figure $25 \mathrm{c}$ the harmonics are present in the signals optimized with ACO, where we observe that the intensity of the power in the harmonics of 01 is greater than in the harmonics of 01 . The amplitude of the power is considered as a frame of reference between the signals. We can conclude that the presence of harmonics in the optimized signals represents the presence of the stimulus frequency in all optimized signals.

The selection of the most discriminating characteristics of the EEG signals is essential for the design of the functional $\mathrm{BCl}$ systems. In order to obtain this characteristics we will use the Discrete Wavelet Transform (DWT) to decompose the signals in the main brain rhythms: $\delta: 0.1-2.7 \mathrm{~Hz}, \theta: 2.70-5.40 \mathrm{~Hz}, \alpha: 5.40-10.80$ $\mathrm{Hz}, \beta: 10.8-21.7 \mathrm{~Hz}$ and $\gamma: 21.7-43.4 \mathrm{~Hz}$. For this, a fourth order wavelet mother, Daubechies (db4) is used. We will make a comparison of the characteristics obtained from original signals and optimized signals.

Figure 26 and 27 represent the brain rhythms obtained from the original signals, Figure 28 to 31 represent the brain rhythms obtained from the optimal signals. The amplitude in delta rhythms is observed to be greater in the signals optimized than the original signals. This means that to have a greater amplitude in the signals, detect events would be more active, because generally the maximum and minimum points of the signal are seeked out. In addition, it is observed in alpha rhythms a greater signal saturation in the originals than in the optimized ones. Signal saturation generally implies signal noise, duplicate components or minimal differences could be considered as equals in later processes as we can observed in (Whitley, 1994). The optimized signals, having a lower saturation, are better adapted for later processes. From these results, we may conclude that in general, the proposed algorithms can be used for the measure extraction process of $\mathrm{BCl}$ system and improve the conditions of delta and alpha rhythms. 
Santiago M. Fernandez-Fraga, Marco Antonio Aceves-Fernandez, José Emilio Vargas Soto, Juan Manuel Ramos

Arreguín; Population-Based Algorithms Applied to Brain-Computer Interfaces upon Steady-State Visual Evoked

Potentials, Transactions on Machine Learning and Artificial Intelligence, Volume 7 No 2 April, (2019); pp: 1-33

Subsequently, a reconstruction of the signals based on the brain rhythms obtained is performed, that is, a signal formed only by the most representative characteristics of the signal is built. For this purpose, SC method to analyze the behavior of the reconstructed signal in relation to the original signal is implemented.

The reconstruction of the signals (extracted) and comparison with the original signals are shown in Figures 32 to 35 , in such figures, it can be observed that in the time domain, both signals show a great similarity with marginal differences between them. SC allows us to make a comparison of the signals in the frequency domain; the results of such comparison are presented later.

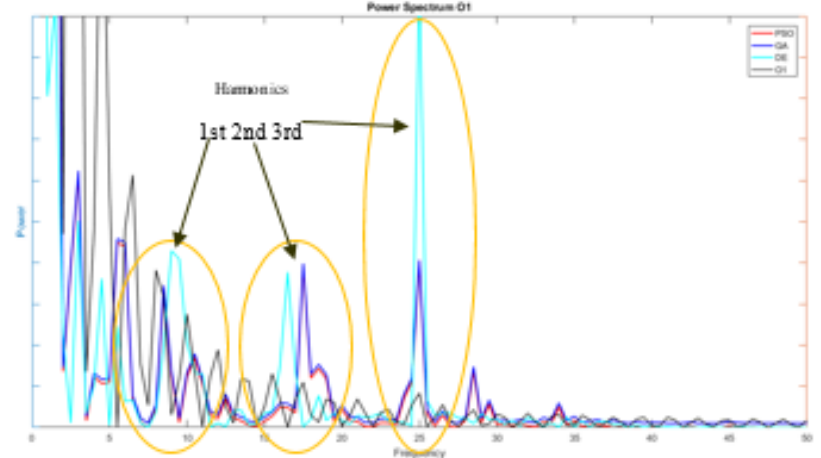

(a)

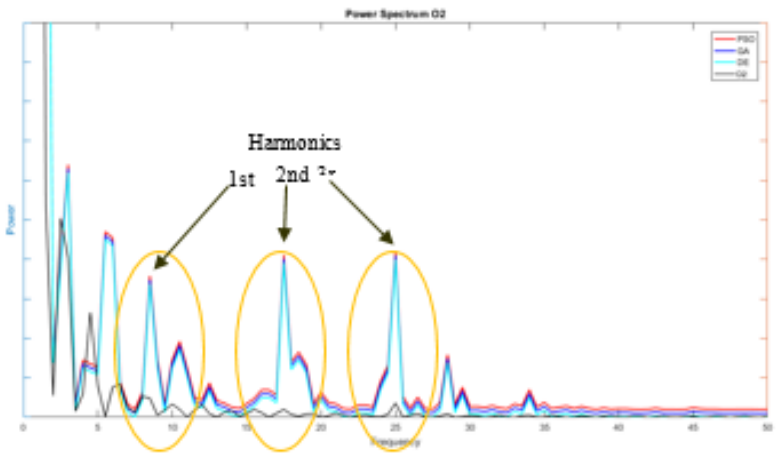

(b)

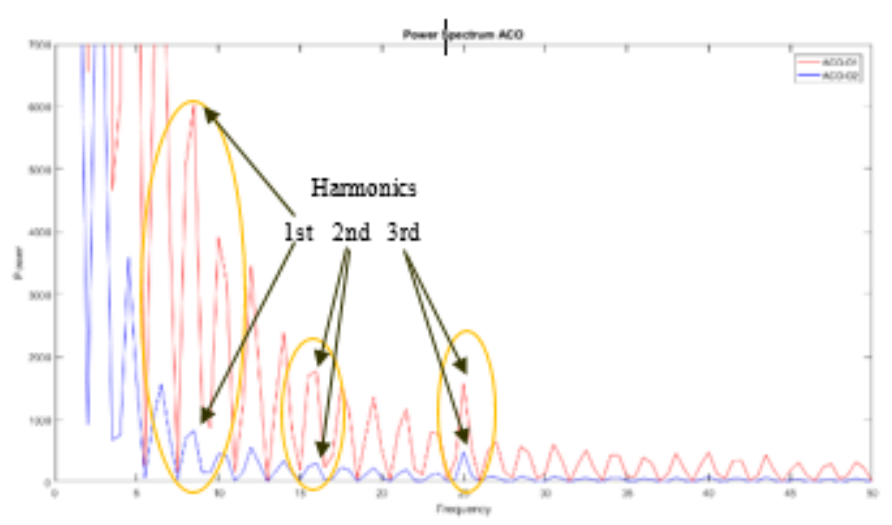

(c)

Figure 25. Power Spectrum signal in the frequency domain. (a) 01 EEG raw and optimal signals. (b) 02 EEG raw and optimal signal. (c) ACO optimal signal. 

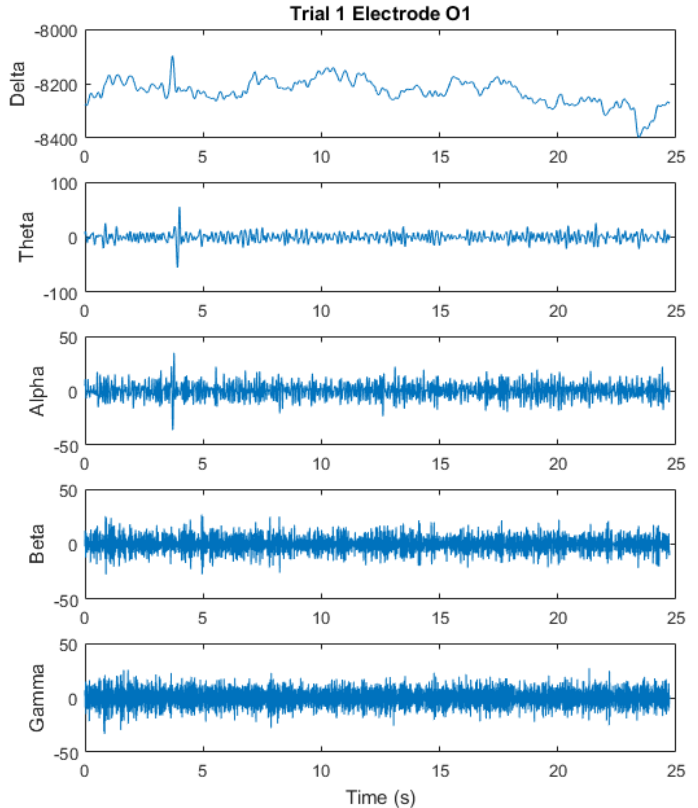
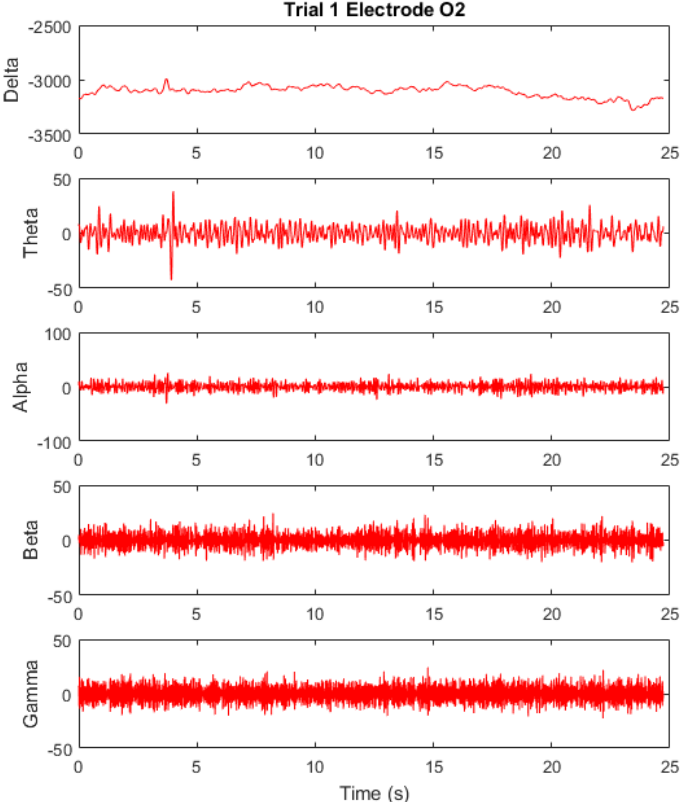

Figure 26. Cerebral rhythms decomposition of the original signals Trial 1.

Figure 27. Cerebral rhythms decomposition of the original signals Trial 2.
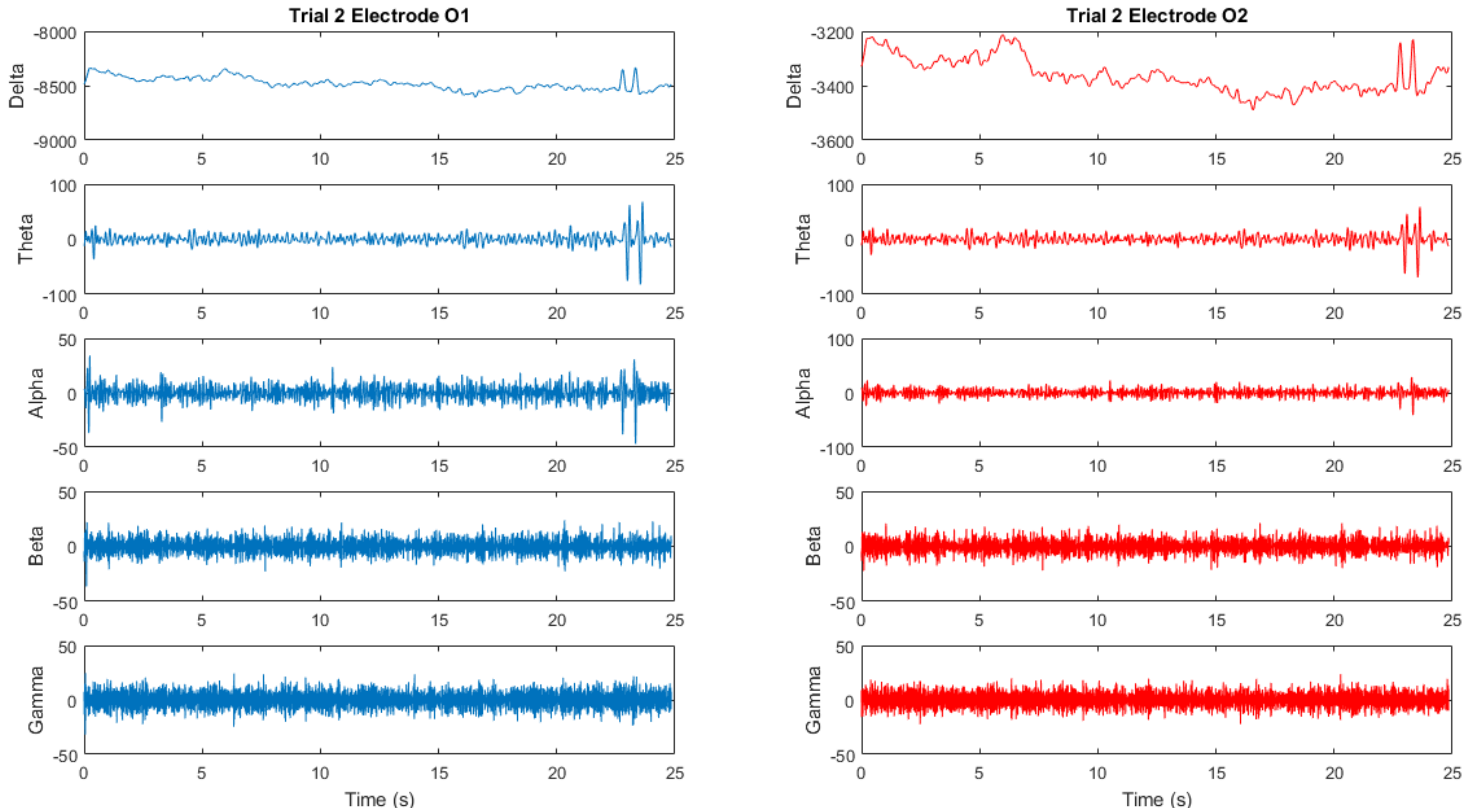

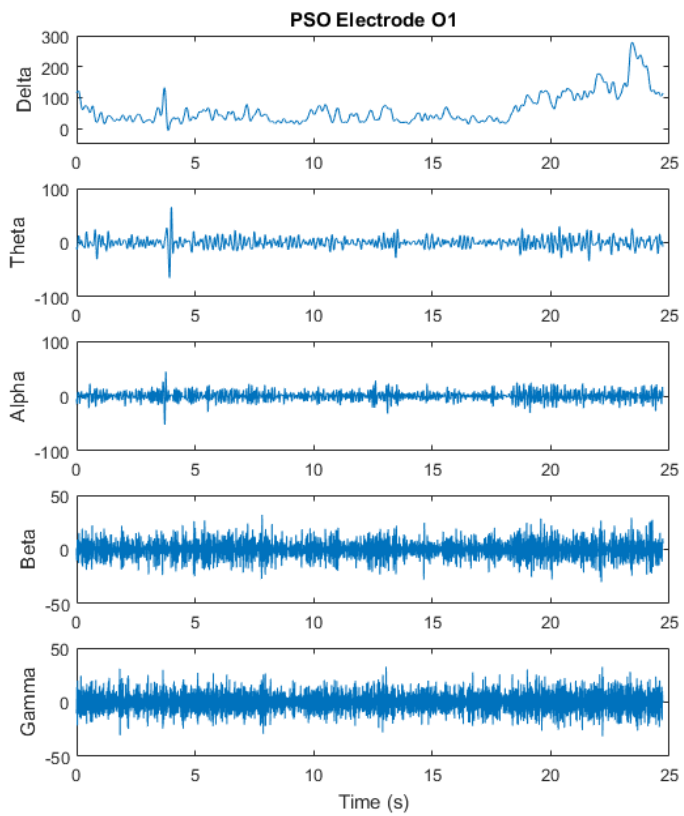
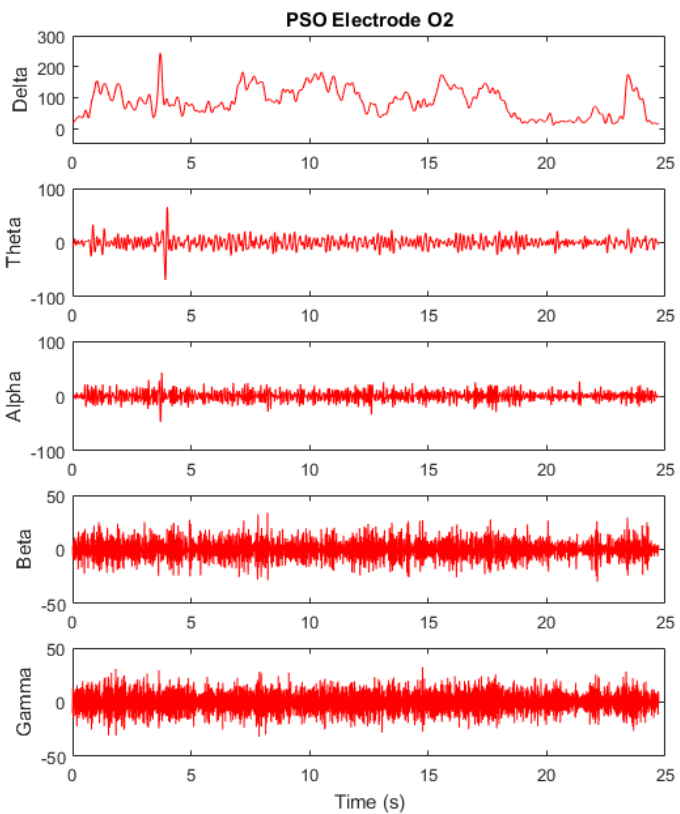

Figure 28. Decomposition of the cerebral rhythms of the signals Optimized by PSO
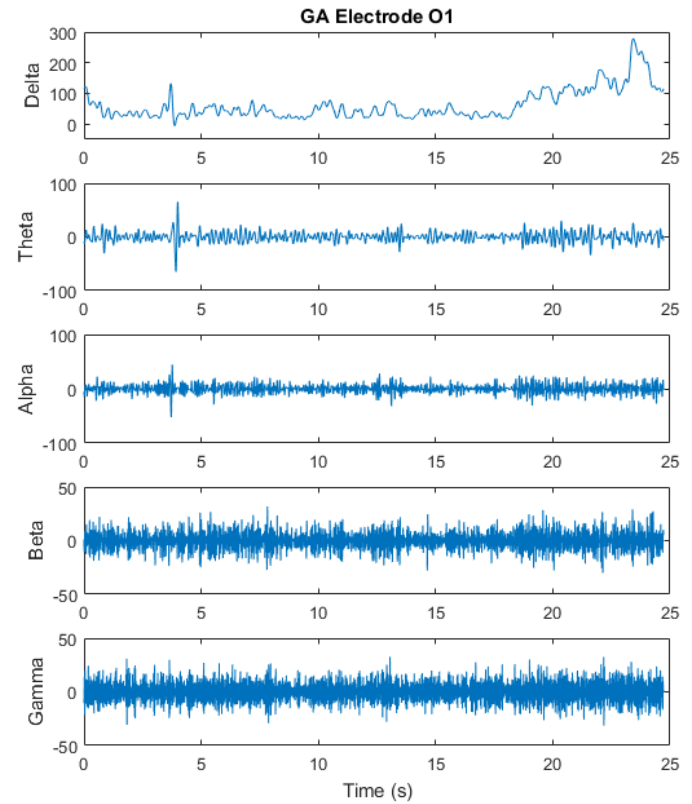
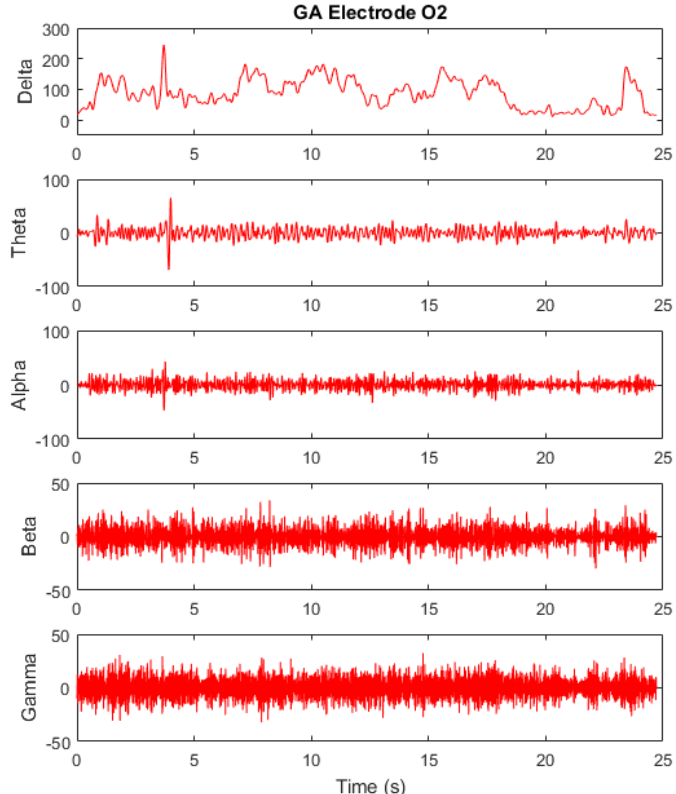

Figure 29. Decomposition of the cerebral rhythms of the signals Optimized by GA. 

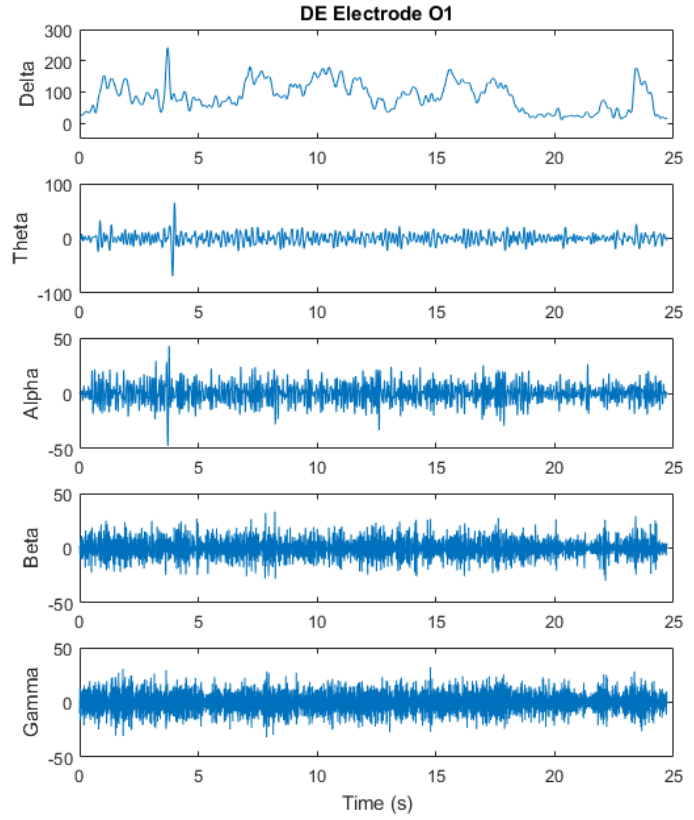
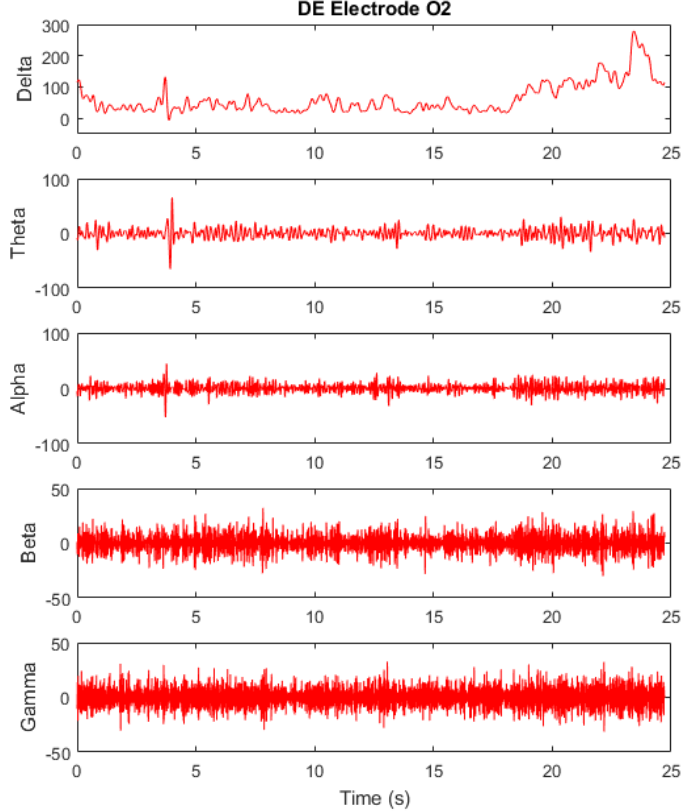

Figure 30. Decomposition of the cerebral rhythms of the signals Optimized by DE.
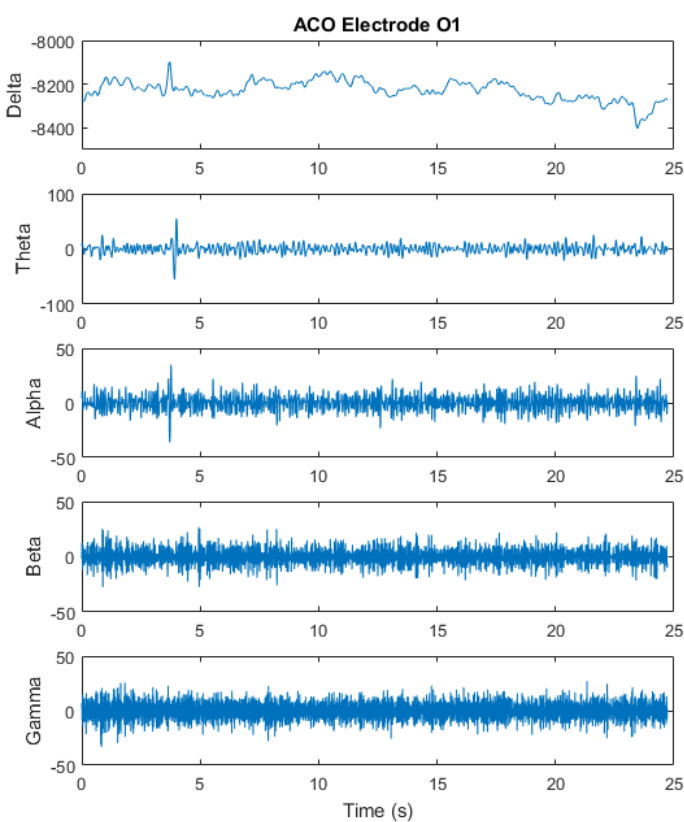
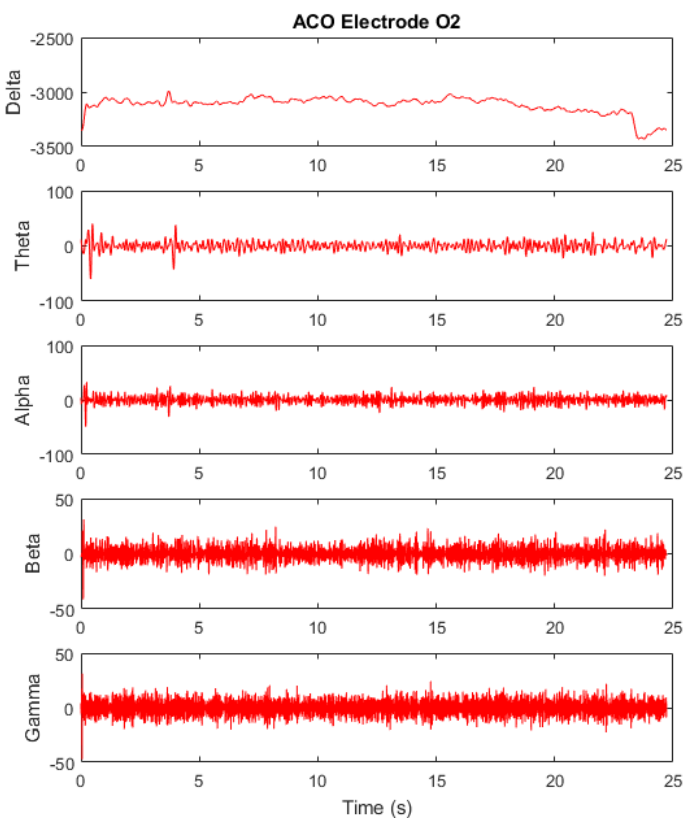

Figure 31. Decomposition of the cerebral rhythms of the signals Optimized by ACO. 
Santiago M. Fernandez-Fraga, Marco Antonio Aceves-Fernandez, José Emilio Vargas Soto, Juan Manuel Ramos Arreguín; Population-Based Algorithms Applied to Brain-Computer Interfaces upon Steady-State Visual Evoked Potentials, Transactions on Machine Learning and Artificial Intelligence, Volume 7 No 2 April, (2019); pp: 1-33
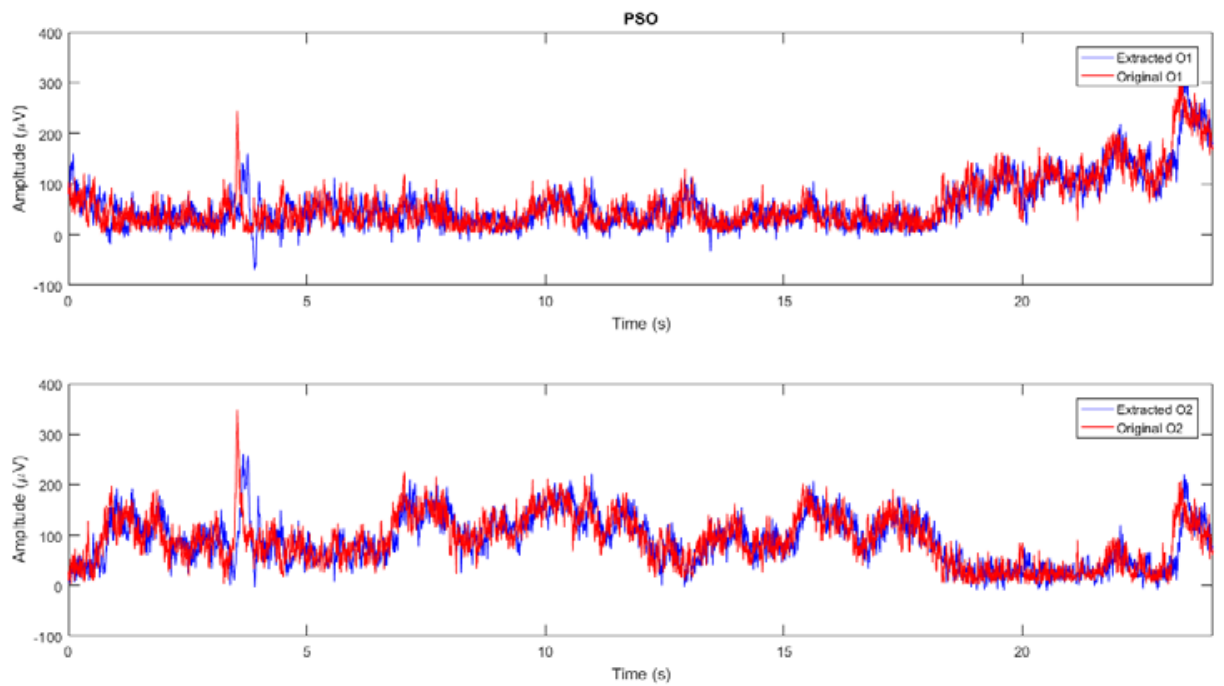

Figure 32. PSO Reconstruction signal based brain rhythms.
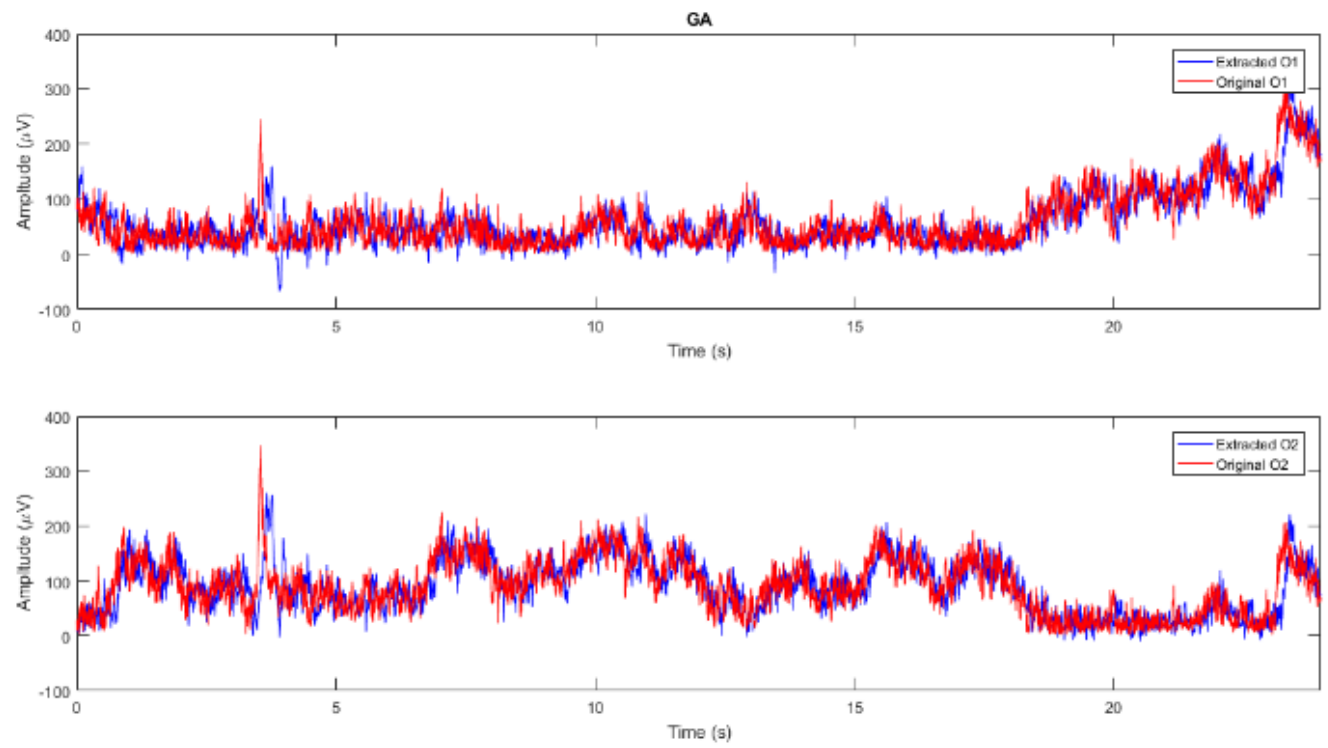

Figure 33. GA Reconstruction signal based brain rhythms. 

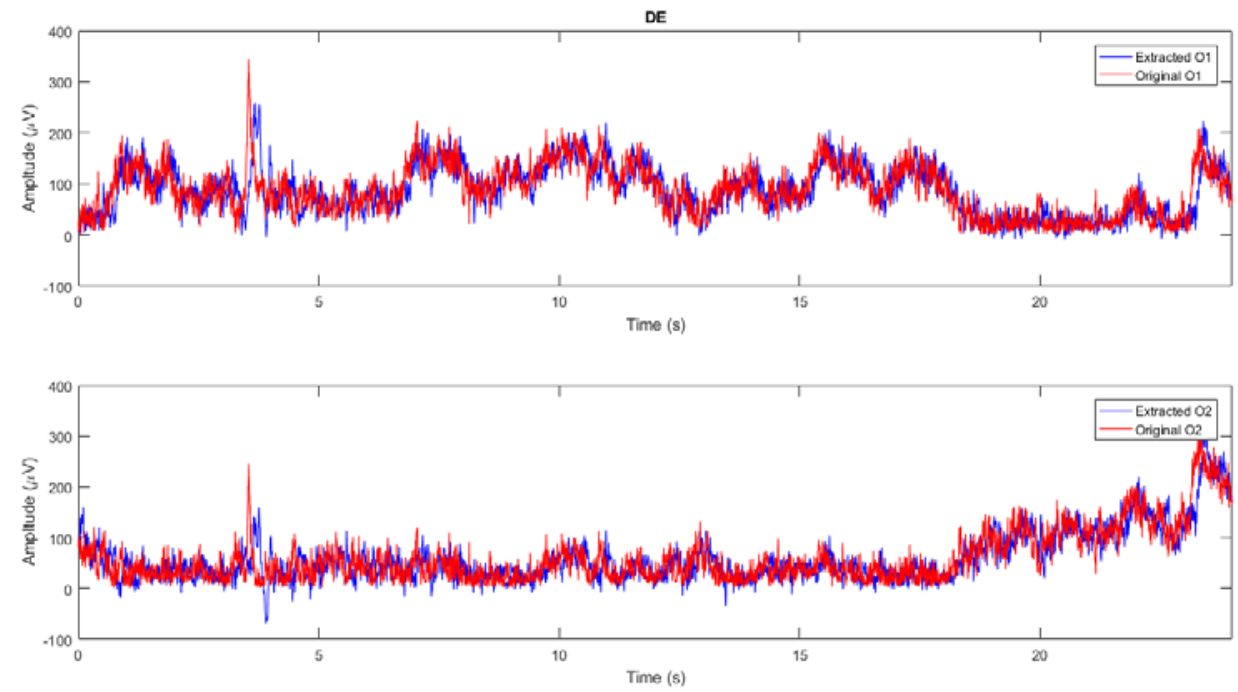

Figure 34. DE Reconstruction signal based brain rhythms.
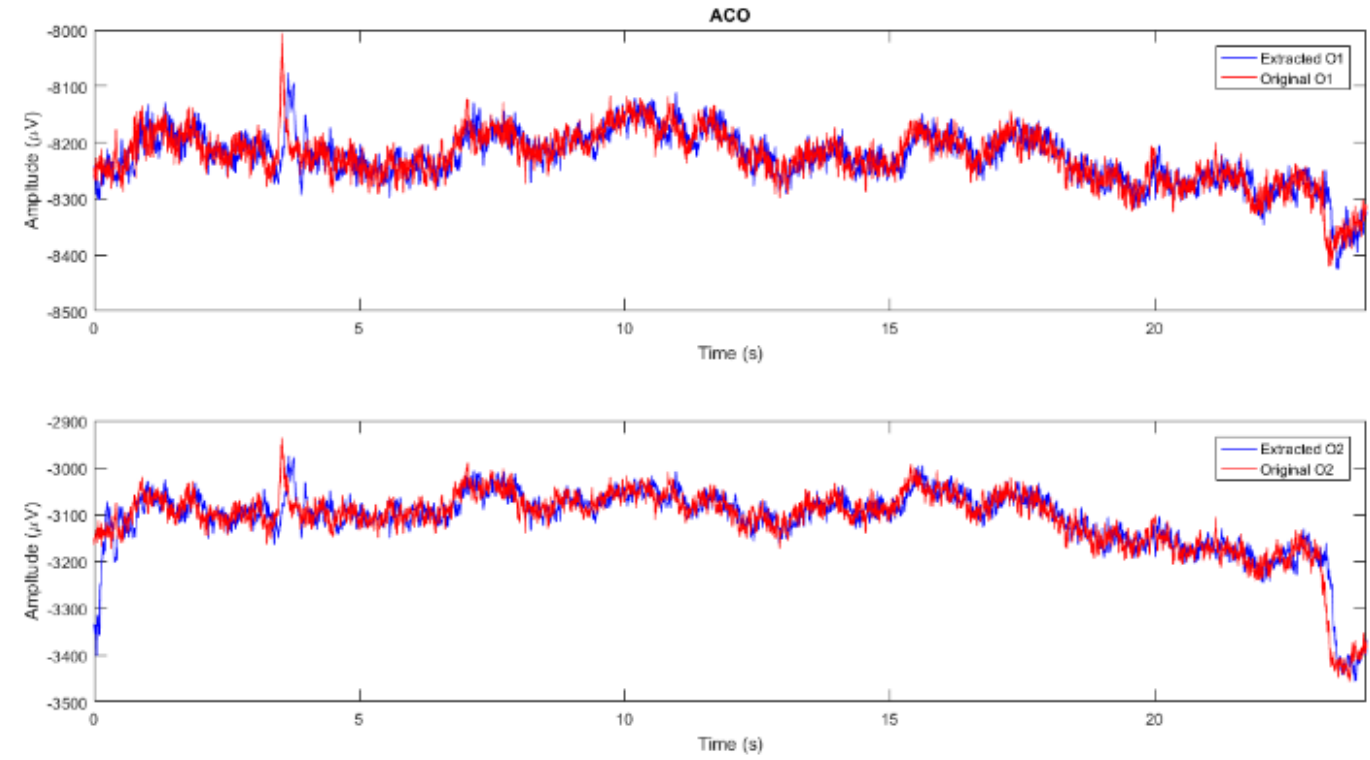

Figure 35. ACO Reconstruction signal based brain rhythms.

Considering the relative consistency between the frequencies of the original signals and the optimizedreconstructed signals (SC), for the case of $\mathrm{O} 1$ (Figure 36a) we observed that PSO, GA and DE SC the frequencies relation is very similar to the original signal. Unlike ACO an identical relation is observed, this we can interpret that the optimized signal is $100 \%$ coherent with the original signal 01-Trial 1 and low coherence with 01-Trial 2. In terms of $\mathrm{O} 2$ (Figure 36b), a low SC behavior is shown for all cases, except $100 \%$ coherence witch $02-T r i a l 1$. We can conclude with respect to the correlation between the optimized signals and the original signals that the SC, for all proposed algorithms is high for $\mathrm{O} 1$ and low for $\mathrm{O2}$, highlighting the outstanding result on ACO in 01.

Table 1 shows a summary of the parameters evaluated for the different algorithms as a frame of reference for the performance of the process of optimization of biomedical electroencephalogram signals based on synchronous SSVEP. 
Santiago M. Fernandez-Fraga, Marco Antonio Aceves-Fernandez, José Emilio Vargas Soto, Juan Manuel Ramos Arreguín; Population-Based Algorithms Applied to Brain-Computer Interfaces upon Steady-State Visual Evoked Potentials, Transactions on Machine Learning and Artificial Intelligence, Volume 7 No 2 April, (2019); pp: 1-33

Table 1. Evaluation Table Summary.

\begin{tabular}{lccccccc}
\hline Algorithm & $\begin{array}{c}\text { No. signals } \\
\text { optimization } \\
\text { process }\end{array}$ & $\begin{array}{c}\text { Process } \\
\text { time } \\
\text { (seconds) }\end{array}$ & $\begin{array}{c}\text { PSD } \\
\text { stimulus } \\
\text { frequency } \\
\text { detect }\end{array}$ & $\begin{array}{c}\text { Harmonics } \\
\text { detection }\end{array}$ & $\begin{array}{c}\text { brain rhythms } \\
\text { decomposition }\end{array}$ & $\begin{array}{c}\text { brain rhythms } \\
\text { reconstruction }\end{array}$ & $\begin{array}{c}\text { spectral } \\
\text { coherence } \\
\text { performance }\end{array}$ \\
\hline PSO-01 & 1 & 134.33 & $\checkmark$ & $\checkmark$ & $\checkmark$ & $\checkmark$ & HIGH \\
PSO-02 & 1 & 134.33 & $\checkmark$ & $\checkmark$ & $\checkmark$ & $\checkmark$ & LOW \\
GA-01 & 1 & $1,048.69$ & $\checkmark$ & $\checkmark$ & $\checkmark$ & $\checkmark$ & HIGH \\
GA-O2 & 1 & $1,048.69$ & $\checkmark$ & $\checkmark$ & $\checkmark$ & $\checkmark$ & LOW \\
DE-O1 & 1 & 848.94 & $\checkmark$ & $\checkmark$ & $\checkmark$ & $\checkmark$ & HIGH \\
DE-O2 & 1 & 848.94 & $\checkmark$ & $\checkmark$ & $\checkmark$ & $\checkmark$ & LOW \\
ACO-O1 & 2 & $4,841.13$ & $\checkmark$ & $\checkmark$ & $\checkmark$ & $\checkmark$ & IDENTICAL \\
ACO-O2 & 2 & $4,693.78$ & $\checkmark$ & $\checkmark$ & $\checkmark$ & $\checkmark$ & IDENTICAL \\
\hline
\end{tabular}
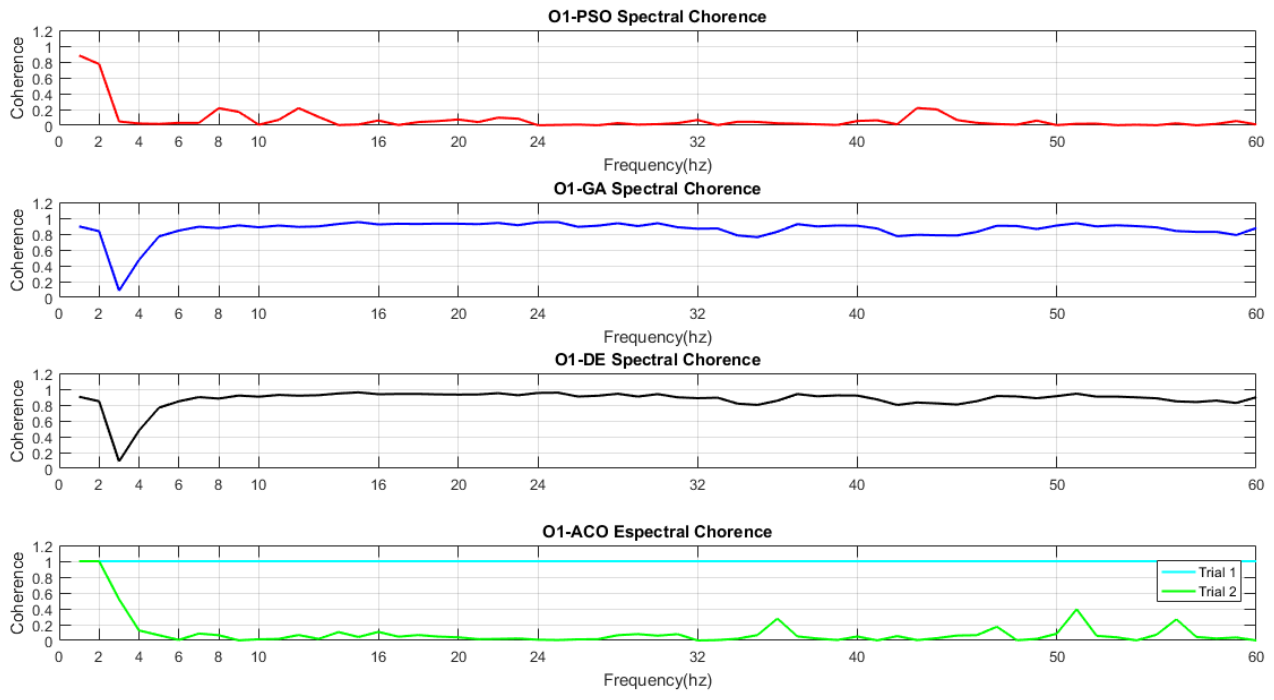

(a)
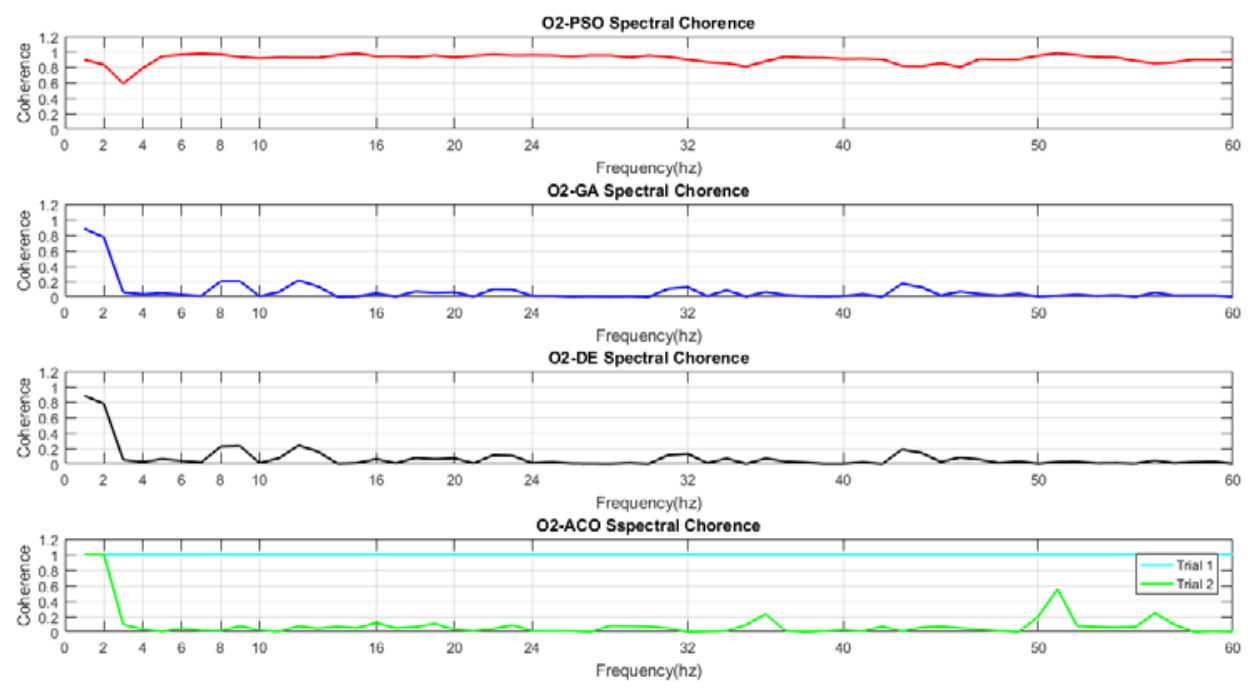

Figure 36. Coherence between the original signals and reconstruction-optimized signals. (a) Electrode 01. (b) Electrode 02. 


\section{Conclusions}

In this contribution, the comparison between PSO, GA, DE and ACO algorithms as a new paradigm for EEG signal processing is presented. It is observed that the performance to find optimal solutions is much faster PSO than the other algorithms, in terms of the computational cost. Optimized signals are good candidates for obtaining cerebral rhythms by improving the measurement power signal and eliminating noise. Likewise, we can observe that the detection of the stimulus frequency was much better in the optimized signals than in the original signal, especially in the 01 electrode. The results show that PSD is a tool that identifies the stimulus frequency, both in the optimized signals and in the original signals. We can also observe that the use of SC to measure the correlation between the optimized signals and the original signals is greater in the $\mathrm{O} 1$ electrode with an outstanding ACO performance in both electrodes. These results allow us to demonstrate that signal optimization using population-based algorithms is a good alternative solution for the processing of EEG signals and to improve the performance of $\mathrm{BCl}$ systems.

Implementing signal-processing techniques that reduce computational cost and solve problems of optimization of complex systems is an important part of the development of new research in the field of bioinformatics. As future work the authors suggest tasks such as comparing algorithms based on populations with the most used methods in $\mathrm{BCl}$ investigations, Canonical Correlation Analysis, Independent Component Analysis, etc., are an opportunity to present new alternatives in the area of biomedical signal processing.

\section{ACKNOWLEDGMENTS}

To Instituto Tecnológico Nacional de México, Instituto Tecnológico de Querétaro and the Universidad Autónoma de Querétaro to the support received for the accomplishment of the present work. To Brain Science Institute, Laboratory for Advanced Brain Signal Processing (RIKEN) and Dr. Hovagim Bakardjian to allowing access to its database of signals used in this work.

\section{CONFLICT OF INTEREST}

The author(s) declare(s) that there is no conflict of interest regarding the publication of this paper.

Table 1. Normalized DCG gains of Google and our fuzzy JEKS algorithm.

\begin{tabular}{|c|c|c|}
\hline Query & Google Ranking & Fuzzy JEKS Algorithm Ranking \\
\hline Q1 & 0.980211 & 0.959274 \\
\hline Q2 & 0.896716 & 0.92342 \\
\hline Q3 & 0.937156 & 0.926431 \\
\hline Q4 & 0.979388 & 0.978542 \\
\hline Q5 & 0.987652 & 0.987472 \\
\hline Q6 & 0.94898 & 0.948706 \\
\hline Q7 & 0.98502 & 0.98638 \\
\hline Q8 & 0.91282 & 0.877635 \\
\hline Q9 & 0.900639 & 0.929049 \\
\hline
\end{tabular}


Santiago M. Fernandez-Fraga, Marco Antonio Aceves-Fernandez, José Emilio Vargas Soto, Juan Manuel Ramos Arreguín; Population-Based Algorithms Applied to Brain-Computer Interfaces upon Steady-State Visual Evoked

Potentials, Transactions on Machine Learning and Artificial Intelligence, Volume 7 No 2 April, (2019); pp: 1-33

We obtained normalized DCG values for the 10 queries for our algorithm as well as for Google results. It can be seen that our algorithm acquires higher values of normalized DCG for 3 queries out of 10 queries when compared to Google.

\section{Conclusion}

In a professional context it often happens that private or corporate clients corder a publication to be made and presented with the actual content still not being ready. Think of a news blog that's filled with con Far far away, behind the word mountains, far from the countries Vokalia and Consonantia, there live the blind texts. Separated they live in Bookmarksgrove right at the coast of the Semantics, a large language ocean. A small river named Duden flows by their place and supplies it with the necessary regelialia. It is a paradisematic country, in which roasted parts of sentences fly into your mouth. Even the all-powerful Pointing has no control about the blind texts it is an almost unorthographic life One day however a small line of blind text by the name of Lorem Ipsum decided to leave for the far World of Grammar. The Big Oxmox advised her not to do so, because there were thousands of bad Commas, wild Question Marks and devious Semikoli, but the Little Blind Text didn't listen. She packed her seven versalia, put her initial into the belt and made herself on the way. When she reached the first hills of the Italic Mountains, she had a last view back on the skyline of her hometown Bookmarksgrove, the headline of Alphabet Village and the subline of her own road, the Line Lane. Pityful a rethoric question ran over her cheek, then

In the future work, we will further improve the algorithm. Blind texts it is an almost unorthographic life One day however a small line of blind text by the name of Lorem Ipsum decided to leave for the far World of Grammar by adding these effects.

\section{REFERENCES}

[1]. Ab Wahab, M. N., Nefti-Meziani, S., \& Atyabi, A. "A comprehensive review of swarm optimization algorithms". (PloS one, 10(5), 2015).

[2]. Adubi, S. A., \& Misra, S. (2014, September). A comparative study on the ant colony optimization algorithms. In Electronics, Computer and Computation (ICECCO), 2014 11th International Conference on (pp. 1-4). IEEE.

[3]. Adubi S. A., and Misra, S. A comparative study on the ant colony optimization algorithms. (Electronics, Computer and Computation (ICECCO), 11th International Conference on IEEE, 2014), pp. 1-4.

[4]. Aggarwal, M., \& Saroj, D. Compute travelling salesman problem using ant colony optimization. (International Journal of Computing and Business Research, 2012), ISSN (Online): 2229-6166 Proceedings of 1-Society 2012 at GKU.

[5]. Ahirwal, M. K., Kumar, A., \& Singh, G. K. "Adaptive filtering of EEG/ERP through noise cancellers using an improved PSO algorithm". (Swarm and Evolutionary Computation, 14, 2014), pp. 7691. 
[6]. Ahirwal, M. K., Kumar, A., \& Singh, G. K. "Analysis and testing of PSO variants through application in EEG/ERP adaptive filtering approach". (Biomedical Engineering Letters, 2(3), 2012), pp. 186197.

[7]. Al-Fahoum, A. S., \& Al-Fraihat, A. A. "Methods of EEG signal features extraction using linear analysis in frequency and time-frequency domains". ISRN Neuroscience, 2014.

[8]. Arcentales, A., Giraldo Giraldo, B., Benito, S., Díaz, I., \& Caminal Magrans, P “Análisis de coherencia y densidad espectral de potencia entre las señales de flujo respiratorio y la variabilidad del ritmo cardiaco en pacientes en proceso de extubación". (XXVII Congreso Anual de la Sociedad Española de Ingeniería Biomédica, 2009), pp. 517-520.

[9]. Atyabi, A., Luerssen, M., Fitzgibbon, S., \& Powers, D. M. “Dimension reduction in EEG data using particle swarm optimization". In Evolutionary Computation (CEC), 2012 IEEE Congress on IEEE, 2012, June, pp. 1-8.

[10]. Atyabi, A., Luerssen, M. H., \& Powers, D. M. “PSO-based dimension reduction of EEG recordings: Implications for subject transfer in BCl”. (Neurocomputing, 119, 2013), pp. 319-331.

[11]. Bakardjian, H., Tanaka, T., \& Cichocki, A. "Optimization of SSVEP brain responses with application to eight-command brain-computer interface". (Neuroscience letters, 469(1) 2010), pp. 34-38.

[12]. Bevilacqua, V., Tattoli, G., Buongiorno, D., Loconsole, C., Leonardis, D., Barsotti, M. \& Bergamasco, M. "A novel BCl-SSVEP based approach for control of walking in virtual environment using a convolutional neural network". In Neural Networks (IJCNN), July 2014 International Joint Conference on IEEE, pp. 4121-4128.

[13]. Castellanos, N. P., \& Makarov, V. A. "Recovering EEG brain signals: artifact suppression with wavelet enhanced independent component analysis". (Journal of neuroscience methods, 158(2), 2006), pp. 300-312.

[14]. Chandra Mohan, B., \& Baskaran, R. Survey on recent research and implementation of ant colony optimization in various engineering applications. (International Journal of Computational Intelligence Systems, 4(4), 2011), pp. 566-582.

[15]. Cinar, E., \& Sahin, F. “New classification techniques for electroencephalogram (EEG) signals and a real-time EEG control of a robot". (Neural Computing and Applications, 22(1), 2013), pp. 2939.

[16]. Daly, I., Nasuto, S. J., \& Warwick, K. "Single tap identification for fast BCl control". (Cognitive neurodynamics, 5(1), 2011), pp. 21-30.

[17]. Das, S., Abraham, A., \& Konar, A. Swarm intelligence algorithms in bioinformatics. (Computational Intelligence in Bioinformatics, Springer Berlin Heidelberg, 2008), pp. 113-147. 
Santiago M. Fernandez-Fraga, Marco Antonio Aceves-Fernandez, José Emilio Vargas Soto, Juan Manuel Ramos

Arreguín; Population-Based Algorithms Applied to Brain-Computer Interfaces upon Steady-State Visual Evoked

Potentials, Transactions on Machine Learning and Artificial Intelligence, Volume 7 No 2 April, (2019); pp: 1-33

[18]. Dobrea, D. M., Dobrea, M. C., \& Costin, M. “An EEG coherence based method used for mental tasks classification". (Computational Cybernetics, 2007. ICCC 2007. IEEE International Conference on IEEE, October 2007), pp. 185-190.

[19]. Dorigo, M., \& Gambardella, L. M. Ant colonies for the travelling salesman problem. (Biosystems, 43(2), 1997), pp. 73-81.

[20]. Dorigo, M., Birattari, M., \& Stutzle, T. Ant colony optimization. (IEEE computational intelligence magazine, 1(4), 2006), pp. 28-39.

[21]. Escalona-Vargas, D. I., Lopez-Arevalo, I., \& Gutiérrez, D. “Multicompare tests of the performance of different metaheuristics in EEG dipole source localization". (The Scientific World Journal, 2014).

[22]. Esqueda Elizondo J. J., Bermúdez Encarnación E. G., Jiménez Beristáin L., Pinto Ramos M. A., Trujillo Toledo D. A., Rojo Ramírez Y., Ruiz Morales A., Munguía Carrillo P. E., Gónzalez Vivas B. A., González Ramírez E. O. "Análisis de Potencia y Coherencia de Señales Electroencefalográficas en el Seguimiento de un Niño con Trastorno del Espectro Autista". (Congr. Int. Ing. Electrón. Mem. ELECTRO, Chihuahua, Chih., México, vol. 38, 2016), pp. 169-174.

[23]. Gan, R., Guo, Q., Chang, H., \& Yi, Y. Improved ant colony optimization algorithm for the traveling salesman problems. (Journal of Systems Engineering and Electronics, 21(2), 2010), pp. 329-333.

[24]. Hema, C. R., Paulraj, M. P., Yaacob, S., Adom, A. H., \& Nagarajan, R. "Functional link PSO neural network based classification of EEG mental task signals". (In Information Technology, 2008. ITSim 2008. International Symposium on IEEE, Vol. 3, August 2008), pp. 1-6.

[25]. Huang, H., Xie, H. B., Guo, J. Y., \& Chen, H. J. Ant colony optimization-based feature selection method for surface electromyography signals classification. (Computers in biology and medicine, 42(1), 2012), pp. 30-38.

[26]. Jiang, M., Jiang, S., Zhu, L., Wang, Y., Huang, W., \& Zhang, H. (2013). Study on parameter optimization for support vector regression in solving the inverse ECG problem. (Computational and mathematical methods in medicine, 2013).

[27]. Kanan, H. R., \& Faez, K. An improved feature selection method based on ant colony optimization (ACO) evaluated on face recognition system. (Applied Mathematics and Computation, 205(2), 2008), pp. 716-725.

[28]. Khushaba, R. N., Al-Ani, A., AlSukker, A., \& Al-Jumaily, A. "A combined ant colony and differential evolution feature selection algorithm". (International Conference on Ant Colony Optimization and Swarm Intelligence, Springer Berlin Heidelberg, September 2008), pp. 1-12.

[29]. Khushaba, R. N., AlSukker, A., Al-Ani, A., \& Al-Jumaily, A. Intelligent artificial ants based feature extraction from wavelet packet coefficients for biomedical signal classification. 
(Communications, Control and Signal Processing, 2008. ISCCSP 2008. 3rd International Symposium on IEEE, March 2008), pp. 1366-1371.

[30]. Kołodziej, M., Majkowski, A., \& Rak, R. J. "A new method of EEG classification for BCl with feature extraction based on higher order statistics of wavelet components and selection with genetic algorithms". (International Conference on Adaptive and Natural Computing Algorithms, Springer Berlin Heidelberg, April 2011), pp. 280-289.

[31]. Lalor, E., Kelly, S. P., Finucane, C., Burke, R., Reilly, R. B., \& McDarby, G. "Brain computer interface based on the steady-state VEP for immersive gaming control". (Biomedizinsche Tecknik, 49(1), 2004), pp. 63-64.

[32]. Lian, H., Qin, Y., \& Liu, J. An Adaptive Differential Evolution Algorithm Based on New Diversity. (International Journal of Computational Intelligence Systems, 6(6), 2013), pp. 1094-1107.

[33]. Lin, Z., Zhang, C., Wu, W., \& Gao, X. (2007). Frequency recognition based on canonical correlation analysis for SSVEP-based BCIs. (IEEE Transactions on Biomedical Engineering, 54(6), 2007), pp. 1172-1176.

[34]. Ma, Y., Ding, X., She, Q., Luo, Z., Potter, T., \& Zhang, Y. (2016). Classification of motor imagery EEG signals with support vector machines and particle swarm optimization. (Computacional and mathematical methods in medicine, 2016).

[35]. Mancera-Galván, E., Garro-Licón, B. A., and Rodríguez-Vázquez, K. Optimización mediante algoritmo de hormigas aplicado a la recolección de residuos sólidos en UNAM-CU. (Research in Computing Science 94, 2015), pp. 163-177.

[36]. Mishra, E. A., Das, D. M., \& Panda, D. T. "Swarm intelligence optimization: editorial survey". (International Journal of Emerging Technology and Advanced Engineering, 3(1), 2013), pp. 217230.

[37]. Mojžíš, F., Kukal, J., \& Švihlík, J. Application of optimization heuristics for complex astronomical object model identification. (Soft Computing, 2014).

[38]. Muñoz, M. A., López, J. A., \& Caicedo, E. F. "Inteligencia de enjambres: sociedades para la solución de problemas (una revisión)”. Ingeniería e Investigación; Vol. 28, núm. 2 (2008); pp. 119-130.

[39]. Rajaguru, H., \& Prabhakar, S. K. "An Exhaustive Analysis of Code Converters as Pre-Classifiers and K means, SVD, PCA, EM, MEM, PSO, HPSO and MRE as Post Classifiers for Classification of Epilepsy from EEG Signals". (Journal of Chemical and Pharmaceutical Sciences, Vol. 9 No. 2, 2016).

[40]. Regan, D. "Steady state evoked potentials". (JOSA, 67(11), 1977), pp. 1475-1489. 
Santiago M. Fernandez-Fraga, Marco Antonio Aceves-Fernandez, José Emilio Vargas Soto, Juan Manuel Ramos

Arreguín; Population-Based Algorithms Applied to Brain-Computer Interfaces upon Steady-State Visual Evoked

Potentials, Transactions on Machine Learning and Artificial Intelligence, Volume 7 No 2 April, (2019); pp: 1-33

[41]. RIKEN, Brain Science Institute, Laboratory for Advanced Brain Signal Processing and Dr. Hovagim Bakardjian.

[42]. Online:http://www.bakardjian.com/work/ssvep_data_Bakardjian.html, (Consulting 2017, January).

[43]. Rodríguez-Piñero, P. T. "Introducción a los algoritmos genéticos y sus aplicaciones". Universidad Rey Juan Carlos, (Servicio de Publicaciones, 2003).

[44]. Sun, T. Y., Liu, C. C., Lin, C. L., Hsieh, S. T., \& Huang, C. S. “A radial basis function neural network with adaptive structure via particle swarm optimization". (Particle Swarm Optimization. InTech, 2009).

[45]. Storn, R., \& Price, K. "Differential evolution-a simple and efficient heuristic for global optimization over continuous spaces". (Journal of global optimization, 11(4), 1997), pp. 341-359.

[46]. Stützle, T., \& Dorigo, M. ACO algorithms for the traveling salesman problem. (Evolutionary algorithms in engineering and computer science, 1999), pp. 163-183.

[47]. Svensson, C. M., Coombes, S., \& Peirce, J. W. (2012). Using evolutionary algorithms for fitting high-dimensional models to neuronal data. (Neuroinformatics, 10(2) 2012), pp. 199-218.

[48]. Tello, R. J., Valadão, C. T., \& Bastos-Filho, T. F. “Control de una Silla de Ruedas Robótica de Alto Rendimiento por Medio de Potenciales Evocados Visuales". (In ACTAS V Congreso Internacional de Turismo para Todos: VI Congreso Internacional de Diseño, Redes de Investigación y Tecnología para todos DRT4ALL, Universidad Internacional de Andalucía 2015), pp. 369-390.

[49]. Thatcher, R. W., North, D., \& Biver, C. "EEG and intelligence: relations between EEG coherence, EEG phase delay and power". (Clinical neurophysiology, 116(9), 2005), pp. 2129-2141.

[50]. Tierra-Criollo, C. J., \& Infantosi, A. F. C. “Coherencia de las Oscilaciones Cerebrales Durante Estimulación del Nervio Tibial". (Memorias II Congreso Latinoamericano de Ingeniería Biomédica. Habana Cuba, 2001).

[51]. Valbuena, D., Cyriacks, M., Friman, O., Volosyak, I., \& Graser, A. "Brain-computer interface for high-level control of rehabilitation robotic systems". In Rehabilitation Robotics, 2007. ICORR 2007. IEEE 10th International Conference on IEEE, June 2007, pp. 619-625.

[52]. Vera, N. P. M. “Evaluación de la conectividad cerebral bajo fármacos mediante análisis no lineal del EEG". (Tesis, Universidad Politécnica de Cataluña, Departamento de Ingeniería de Sistemas Automación e Informática Industrial. Barcelona España, 2009).

[53]. Wang, Y., \& Jung, T. P. "Visual stimulus design for high-rate SSVEP BCl". (Electronics letters, 46(15), 2010), pp. 1057-1058. 
[54]. Whitley, D. “A genetic algorithm tutorial”. (Statistics and computing, 1994), 4(2), pp. 65-85.

[55]. Yu, S., Wei, Y. M., \& Wang, K. "A PSO-GA optimal model to estimate primary energy demand of China". (Energy Policy, 42, 2012), pp. 329-340.

[56]. Yu, X., Liu, J., \& Li, H. “An adaptive inertia weight particle swarm optimization algorithm for IIR digital filter". In Artificial Intelligence and Computational Intelligence, November 2009. AICI'09. International Conference on IEEE, Vol. 1, pp. 114-118.

[57]. Yun, H. Y., Jeong, S. J., \& Kim, K. S. Advanced harmony search with ant colony optimization for solving the traveling salesman problem. (Journal of Applied Mathematics, 2013).

[58]. Zhang, Y., Dong, L., Zhang, R., Yao, D., Zhang, Y., \& Xu, P. (2014). An efficient frequency recognition method based on likelihood ratio test for SSVEP-based $\mathrm{BCI}$. (Computational and mathematical methods in medicine, 2014).

[59]. Zhu, D., Bieger, J., Molina, G. G., \& Aarts, R. M. "A survey of stimulation methods used in SSVEPbased BCls". (Computational Intelligence and Neuroscience, 2010). 